\title{
Induced Systemic Resistance (ISR) and Fe Deficiency Responses in Dicot Plants
}

\author{
Francisco J. Romera ${ }^{*}$, María J. García ${ }^{2}$, Carlos Lucena ${ }^{2}$, Ainhoa Martínez-Medina ${ }^{3}$, \\ Miguel A. Aparicio', José Ramos ${ }^{4}$, Esteban Alcántara ${ }^{1}$, Macarena Angulo ${ }^{1}$ and \\ Rafael Pérez-Vicente ${ }^{2}$ \\ ${ }^{1}$ Department of Agronomy, Campus de Excelencia Internacional Agroalimentario CeiA3, Universidad de Córdoba, Córdoba, \\ Spain, ${ }^{2}$ Department of Botany, Ecology and Plant Physiology, Campus de Excelencia Internacional Agroalimentario CeiA3, \\ Universidad de Córdoba, Córdoba, Spain, ${ }^{3}$ Molecular Interaction Ecology, German Centre for Integrative Biodiversity \\ Research (iDiv) Halle-Jena-Leipzig, Leipzig, Germany, ${ }^{4}$ Department of Microbiology, Campus de Excelencia Internacional \\ Agroalimentario CeiA3, Universidad de Córdoba, Córdoba, Spain
}

\section{OPEN ACCESS}

Edited by:

Thomas J. Buckhout, Humboldt-Universität zu Berlin, Germany

Reviewed by:

Christos Zamioudis, Democritus University of Thrace,

Greece

Louis Grillet,

Academia Sinica, Taiwan

*Correspondence:

Francisco J. Romera ag1roruf@uco.es

Specialty section: This article was submitted to Plant Nutrition, a section of the journal Frontiers in Plant Science

Received: 19 December 2018 Accepted: 21 February 2019

Published: 11 March 2019

Citation:

Romera FJ, García MJ, Lucena C, Martínez-Medina A, Aparicio MA,

Ramos J, Alcántara E, Angulo $M$ and Pérez-Vicente $R$ (2019) Induced Systemic Resistance (ISR) and Fe Deficiency Responses in Dicot Plants.

Front. Plant Sci. 10:287. doi: 10.3389/fp/s.2019.00287
Plants develop responses to abiotic stresses, like Fe deficiency. Similarly, plants also develop responses to cope with biotic stresses provoked by biological agents, like pathogens and insects. Some of these responses are limited to the infested damaged organ, but other responses systemically spread far from the infested organ and affect the whole plant. These latter responses include the Systemic Acquired Resistance (SAR) and the Induced Systemic Resistance (ISR). SAR is induced by pathogens and insects while ISR is mediated by beneficial microbes living in the rhizosphere, like bacteria and fungi. These root-associated mutualistic microbes, besides impacting on plant nutrition and growth, can further boost plant defenses, rendering the entire plant more resistant to pathogens and pests. In the last years, it has been found that ISReliciting microbes can induce both physiological and morphological responses to $\mathrm{Fe}$ deficiency in dicot plants. These results suggest that the regulation of both ISR and Fe deficiency responses overlap, at least partially. Indeed, several hormones and signaling molecules, like ethylene (ET), auxin, and nitric oxide (NO), and the transcription factor MYB72, emerged as key regulators of both processes. This convergence between ISR and Fe deficiency responses opens the way to the use of ISR-eliciting microbes as Fe biofertilizers as well as biopesticides. This review summarizes the progress in the understanding of the molecular overlap in the regulation of ISR and Fe deficiency responses in dicot plants. Root-associated mutualistic microbes, rhizobacteria and rhizofungi species, known for their ability to induce morphological and/or physiological responses to Fe deficiency in dicot plant species are also reviewed herein.

Keywords: dicotyledons, ethylene, iron, ISR, rhizobacteria, rhizofungi, rhizosphere, stress responses

\section{INTRODUCTION}

In the last decades, crop productivity has been mainly based on the use of high-yielding varieties and in the application of high amounts of fertilizers and pesticides. Despite crop protection measures, current losses are estimated at $20-40 \%$ for the major food crops world-wide (Savary et al., 2012). Hence, novel strategies for crop production, with less reliance on chemical products need to be developed. In relation to plant mineral nutrition, two strategies that can contribute to 
this goal are the development of crop varieties more efficient in nutrient acquisition and better management of the rhizosphere (Shen et al., 2013). The rhizosphere, the soil volume influenced by the root system, is one of the most energy-rich habitats on Earth, allowing the life of a myriad of microbes (Pieterse et al., 2014; Pii et al., 2015). Many of them are pathogenic and threaten plant growth. However, there are also many others that are beneficial for plants, like rhizobacteria ("PGPB or PGPR: Plant GrowthPromoting Bacteria or Rhizobacteria") and fungi ("PGPF: Plant Growth-Promoting Fungi"), which can improve plant growth and benefit the adaptation of plants to adverse conditions (Yang et al., 2008; de Zelicourt et al., 2013; Pieterse et al., 2014; Pii et al., 2015; Verbon and Liberman, 2016). Some rhizosphere microbes can have negative effects on plant mineral nutrition, for example, by competing with plants for some nutrients. However, several genera of the rhizosphere microbiota can facilitate nutrient acquisition by plants, thus having positive effects. These beneficial microbes include, among others, mycorrhizal fungi and Rhizobium, which establish mutualistic symbiosis with plant roots that improve phosphorus $(\mathrm{P})$ or nitrogen $(\mathrm{N})$ nutrition, respectively (Guinel, 2015; Wang W. et al., 2017). Additionally, there are free-living mutualistic microbes that can improve plant nutrition through different mechanisms, such as the release of nutrient solubilizing compounds or the modification of root physiology and architecture (Jin et al., 2014; Mimmo et al., 2014; Zamioudis et al., 2014, 2015; Contreras-Cornejo et al., 2015; Li et al., 2015; Pii et al., 2015; García-López et al., 2016; GarnicaVergara et al., 2016; Verbon et al., 2017).

Among the essential mineral nutrients required by plants, iron (Fe), along with $\mathrm{P}$ and $\mathrm{N}$, represent the major constraints for crop productivity worldwide (Pii et al., 2015; Scagliola et al., 2016; Tsai and Schmidt, 2017b). Iron deficiency is widely distributed, mainly in calcareous soils (approximately one third of cultivated lands) which are abundant in arid and semiarid regions (Briat et al., 2015). To cope with Fe deficiency, plants develop morphological and physiological responses, mainly in their roots, aimed to facilitate its acquisition (see following Section; Kobayashi and Nishizawa, 2012; Brumbarova et al., 2015; Lucena et al., 2015). Despite these responses, in many cases it is necessary to apply Fe fertilizers to correct Fe deficiency. For Fe supply in the field, the most common practice is the application of Fe chelates to soils, which are generally expensive and therefore restricted to high added-value field-grown crops (Briat et al., 2015). An alternative is the use of more Fe efficient plant genotypes. However, different results obtained with sterile soils have shown that, even with these genotypes, the cooperation of rhizosphere microbes is necessary for an adequate Fe acquisition (Jin et al., 2014; Pii et al., 2015).

Several studies demonstrated that the application of some beneficial microbes to soils can improve the $\mathrm{Fe}$ nutrition of plants (de Santiago et al., 2009, 2013; Zhang et al., 2009; Freitas et al., 2015; Li et al., 2015; Ipek et al., 2017; Sonbarse et al., 2017; Aras et al., 2018; Arikan et al., 2018). However, the main mechanisms driving such effects are complex and not fully understood. One possible mechanism is the release of Fe solubilizing compounds to soils (Jin et al., 2014; Mimmo et al., 2014; Pii et al., 2015). Moreover, the rhizosphere mutualistic microbiota can also improve plant Fe uptake by the alteration of the root physiology and architecture (Zamioudis et al., 2014, 2015; Contreras-Cornejo et al., 2015; Garnica-Vergara et al., 2016; Scagliola et al., 2016; Verbon et al., 2017). In the last years it has been found that some rhizosphere microbes can induce physiological and morphological responses in roots of dicot plants similar to the ones induced by plants under Fe deficiency (Zhang et al., 2009; Orozco-Mosqueda et al., 2013; Jin et al., 2014; Pieterse et al., 2014; Zamioudis et al., 2014, 2015; Zhao et al., 2014; Pii et al., 2016b; Zhou et al., 2016a; Martínez-Medina et al., 2017; Verbon et al., 2017). It is remarkable that these rhizosphere microbes are also capable of eliciting the Induced Systemic Resistance (ISR) against pathogens and insects. This observation suggests that both processes (ISR and Fe deficiency responses) might be closely interconnected, and opens new possibilities for optimizing the management of the rhizosphere microbiota for improving Fe nutrition and health (Pieterse et al., 2014; Zamioudis et al., 2014, 2015; Verbon et al., 2017). However, the nodes of convergence between the two processes remain unclear.

Elucidating the main nodes of interconnection between the pathways regulating microbe-elicited ISR and Fe uptake is critical for optimizing the use of plant mutualistic microbes in agriculture. This review summarizes the progress in the understanding of the molecular overlap in the regulation of ISR and Fe deficiency responses in dicot plants. We further describe and evaluate rhizobacteria and rhizofungi species, known for their ability to induce morphological and/or physiological responses to Fe deficiency in dicot plants and with potential for a future use as Fe biofertilizers.

\section{Fe DEFICIENCY RESPONSES IN DICOT PLANTS}

Iron ( $\mathrm{Fe})$ is abundant in most soils, mainly as $\mathrm{Fe}^{3+}$, although its availability to plants is low, especially in calcareous soils (Briat et al., 2015). Based on the mechanisms used by plant roots to facilitate mobilization and uptake of $\mathrm{Fe}$, plants are classified into Strategy I species (dicots and non-grass monocots) and Strategy II species (grasses; Kobayashi and Nishizawa, 2012; Ivanov et al., 2012). Dicots, such as Arabidopsis and tomato, are Strategy I species which have to reduce $\mathrm{Fe}^{3+}$ to $\mathrm{Fe}^{2+}$ at the root surface, by means of a ferric reductase (encoded by FRO2 in Arabidopsis), prior to its subsequent uptake through a $\mathrm{Fe}^{2+}$ transporter (encoded by IRT1 in Arabidopsis; Ivanov et al., 2012; Kobayashi and Nishizawa, 2012). This review is devoted to dicots, where ISR mechanisms have been more extensively studied (Balmer et al., 2013). Consequently, the mechanisms described thereafter correspond to Strategy I plant species. For details about the Strategy II plant species readers are referred to other articles in this special issue.

When grown under Fe deficiency, Strategy I species develop several physiological and morphological responses, mainly in roots, known as Fe deficiency responses. Those responses are aimed at facilitating Fe mobilization and uptake (Ivanov et al., 2012; Kobayashi and Nishizawa, 2012; Brumbarova et al., 2015; Lucena et al., 2015). Among the physiological responses are: an enhanced ferric reductase activity due to upregulation of the FRO 
genes; an enhanced $\mathrm{Fe}^{2+}$ uptake capacity due to upregulation of the IRT1 genes; the acidification of the rhizosphere due to upregulation of $A H A$ or $H A\left(\mathrm{H}^{+}\right.$-ATPase) genes (Waters et al., 2007; Brumbarova et al., 2015; Lucena et al., 2015); an increase of the synthesis and release of organic acids, like citrate and malate, to the medium (Kabir et al., 2012; Schmidt et al., 2014); an increase of the synthesis and release of phenolic compounds to the medium due to upregulation of genes like $F 6^{\prime} \mathrm{H1}, \mathrm{S} 8 \mathrm{H}$, BGLU42, and ABCG37 (Schmid et al., 2014; Schmidt et al., 2014; Zamioudis et al., 2014; Tsai and Schmidt, 2017a; Siwinska et al., 2018; Tsai et al., 2018); and an increase of the synthesis and release of flavins to the medium (Rodríguez-Celma and Schmidt, 2013). The acidification facilitates the solubilisation of $\mathrm{Fe}$ and the functioning of the ferric reductase which has an optimum pH around 5.0 (Lucena et al., 2007; Waters et al., 2007). Organic acids can act as chelating agents for $\mathrm{Fe}$ in the soil and also inside the plant (Durrett et al., 2007; Schmidt et al., 2014). In fact, Fe is moved through the xylem chelated with citrate (Durrett et al., 2007; Schmidt et al., 2014). Phenolic compounds, like coumarins, and flavins can act as chelating and reducing agents of $\mathrm{Fe}^{3+}$, thus facilitating its mobilization in the rhizosphere (RodríguezCelma and Schmidt, 2013; Tsai and Schmidt, 2017a; Rajniak et al., 2018). The F6'H1 ("Feruloyl-CoA 6'-Hydroxylase1") and $S 8 H$ ("Scopoletin 8-Hydroxylase") genes encode enzymes involved in the last steps of the synthesis of the coumarins scopoletin and fraxetin (Schmid et al., 2014; Schmidt et al., 2014; Tsai and Schmidt, 2017a; Siwinska et al., 2018; Tsai et al., 2018). The $A B C G 37$ gene (also named PDR9) encodes an ABC transporter involved in the release of coumarins to the medium (Fourcroy et al., 2014, 2016; Zamioudis et al., 2014) while the BGLU42 gene encodes a $\beta$-glucosidase, possibly required for the processing of glycosylated phenolic compounds as an essential step for their secretion in the root vicinity (Zamioudis et al., 2014; Stringlis et al., 2018b). Among the morphological responses are: development of subapical root hairs, cluster roots, and transfer cells, all of which are aimed to increase the surface of contact with the soil (Römheld and Marschner, 1986; Lucena et al., 2015; Romera et al., 2017). Both physiological and morphological responses are mainly located in the subapical regions of the roots (Römheld and Marschner, 1986).

The regulation of the physiological and morphological responses described above is not fully understood but in the last years several transcription factors (TFs) that participate in the activation of most of their associated genes have been described (Ivanov et al., 2012; Kobayashi and Nishizawa, 2012; Brumbarova et al., 2015; Zhang et al., 2015; Li et al., 2016; Liang et al., 2017). In Arabidopsis, the master regulator of most of these genes is FIT (bHLH29), homolog of the tomato FER (Bauer et al., 2007 and references therein). The FIT regulatory network comprises other bHLH TFs of the Ib subgroup, such as bHLH38, bHLH39, bHLH100, and bHLH101. All of them have redundant functions and can interact with FIT to form heterodimers that activate the expression of the Fe acquisition genes FRO2 and IRT1 (Yuan et al., 2008; Wang N. et al., 2013; Brumbarova et al., 2015). FIT/FER is induced in roots in response to Fe deficiency while the other Ib bHLH genes cited above are induced in both roots and leaves in response to Fe deficiency (Brumbarova et al., 2015 and references therein). FIT also controls MYB10 and MYB72, two other TFs essential for plant growth on low Fe conditions (Palmer et al., 2013; Zamioudis et al., 2014, 2015). Besides the FIT/Ib bHLH regulatory network, there is another regulatory network related to the POPEYE (PYE; bHLH47) TF and associated with the vasculature (Brumbarova et al., 2015). In the last years, it has been found that, under Fe-deficiency conditions, IVc subgroup bHLH TFs [bHLH34, bHLH104, bHLH105(ILR3), and bHLH115] activate FIT/bHLH38/39/100/101 and PYE expression (Zhang et al., 2015; Li et al., 2016; Liang et al., 2017). Upstream of the IVc subgroup bHLH TFs is the BRUTUS (BTS) protein, which possesses Fe-binding domains and that interacts with IVc bHLH TFs, targeting them for proteasomal degradation (Zhang et al., 2015; Liang et al., 2017). Since the IVc bHLH TFs act as positive regulators of $\mathrm{Fe}$ deficiency responses, the current data suggests that BTS is a negative regulator of Fe deficiency responses (Zhang et al., 2015; Hindt et al., 2017).

The mechanisms by which plants perceive Fe deficiency and how this perception is transmitted to the activation of the responses is not fully understood. Several studies support a role for hormones and other plant signaling molecules in the activation of FIT and other TFs and, consequently, in the upregulation of the ferric reductase, the $\mathrm{Fe}^{2+}$ transporter and other Fe-related genes. Within them, the plant hormone ethylene (ET) has been found to play a key role in the regulation of most of the physiological and morphological responses to $\mathrm{Fe}$ deficiency (Figure 1; reviewed in Lucena et al., 2015; Li and Lan, 2017; Romera et al., 2017). Besides ET, auxin, nitric oxide (NO), sucrose, and glutathione (GSH) have also been involved in the regulation of Fe deficiency responses; all of them increase in Fe-deficient roots although their specific roles are not fully understood (Romera et al., 1999, 2011, 2017; Lucena et al., 2006, 2015; Graziano and Lamattina, 2007; Waters et al., 2007; Bacaicoa et al., 2009, 2011; García et al., 2010, 2011; Chen et al., 2010; Lingam et al., 2011; Meiser et al., 2011; Koen et al., 2012; Yang et al., 2014; Shanmugam et al., 2015; Lin et al., 2016; Li and Lan, 2017; Kailasam et al., 2018). By contrast to these activating signals, other ones have been implicated in the suppression of Fe deficiency responses, like cytokinins (Séguéla et al., 2008), jasmonic acid (JA; Maurer et al., 2011), brassinosteroids (Wang et al., 2012), and some phloem Fe-related signals (García et al., 2013 , 2018). To integrate both positive and negative signals in the regulation of Fe acquisition genes in roots, a model has been proposed where auxin/ET/NO would act as activators of their expression, while LODIS ("LOng Distance Iron Signal": a phloem Fe-related signal) would act to repress them (Lucena et al., 2006; García et al., 2011, 2018; Romera et al., 2011, 2017).

\section{INDUCED SYSTEMIC RESISTANCE (ISR)}

Besides responses to abiotic stresses, plants also respond to biotic stresses provoked by biological agents, like pathogens or insects (Pieterse et al., 2014; Martínez-Medina et al., 2017; Verbon et al., 2017). Some of these responses are localized but others are systemic, spreading far from the attacked organ and inducing defensive responses in the entire 
plant (Pieterse et al., 2014; Verbon et al., 2017). Within this second possibility, induced resistance is a physiological state of enhanced defensive capacity of the plant triggered by biological or chemical inducers, which protects plant tissues not exposed to the initial attack against future attack by pathogens and herbivorous insects (Van Loon et al., 1998). Induced resistance can be triggered in plants by the infection of pathogens, in response to insect herbivory, or upon root colonization by certain rhizosphere mutualistic microbes. Two of the most studied forms of induced resistance are SAR (Systemic Acquired Resistance), triggered by plant pathogens, and ISR, triggered by root-colonizing mutualistic microbes, like Pseudomonas simiae (syn. Pseudomonas fluorescens), Paenibacillus polymyxa, or Trichoderma spp. (Table 1; Zhang et al., 2009; Pieterse et al., 2012, 2014; Alizadeh et al., 2013; Zamioudis et al., 2014, 2015; Zhao et al., 2014; Martínez-Medina et al., 2017; Verbon et al., 2017). SAR and ISR are mainly differentiated on the basis of the elicitor and the regulatory pathways involved, though the signaling pathways that regulate SAR and ISR share some components (Pieterse et al., 1998, 2002, 2012, 2014; Van Loon et al., 1998; Choudhary et al., 2007).

Over the last years, SAR and ISR have been extensively reviewed (Van Loon et al., 1998; Choudhary et al., 2007; Pieterse et al., 2012, 2014), so here we only discuss major principles in both responses. In systemic tissues, SAR is characterized by increased levels of the hormone salicylic acid (SA) which, through the redox-regulated protein NON-EXPRESSOR OF $P R$ GENES1 (NPR1), activates the expression of a large set of PATHOGENESIS-RELATED (PR) genes, involved in defense responses (Figure 1; Pieterse et al., 1998, 2002, 2012, 2014; Van Loon et al., 1998; Choudhary et al., 2007). By contrast to SAR, ISR is generally mediated by an SA-independent pathway where JA and ET are the central players, and typically functions without $P R$ gene activation (Figure 1; Pieterse et al., 1998, 2002, 2012, 2014; Van Loon et al., 1998; Choudhary et al., 2007). Despite these differences, it has been shown that NPR1 is also required for the JA/ET-dependent ISR triggered by rhizosphere microbes although its role seems to be different in both processes (Figure 1; Pieterse et al., 2014; Nie et al., 2017). In SA signaling, NPR1 is related to a function in the nucleus while in JA/ET signaling it is related to a cytosolic function (Pieterse et al., 2014). Despite these general differences, in some particular cases, ISR can require SA accumulation (Ryu et al., 2003; Alizadeh et al., 2013). Moreover, the signaling pathways involved in the induction of ISR can be different depending on the microbial species and the plant species (Ryu et al., 2003; Jankiewicz and Koltonowicz, 2012; Alizadeh et al., 2013).

The discovery of ISR occurred around 1991, when several researchers showed that root colonization by certain nonpathogenic bacterial races promoted the health of plants upon the stimulation of their defense responses (reviewed in Pieterse et al., 2014). After these pioneering works with bacteria, ISR was further extended to rhizosphere fungi, like Trichoderma spp. or Piriformospora indica (Table 1; Segarra et al., 2009; Alizadeh et al., 2013; Pieterse et al., 2014).

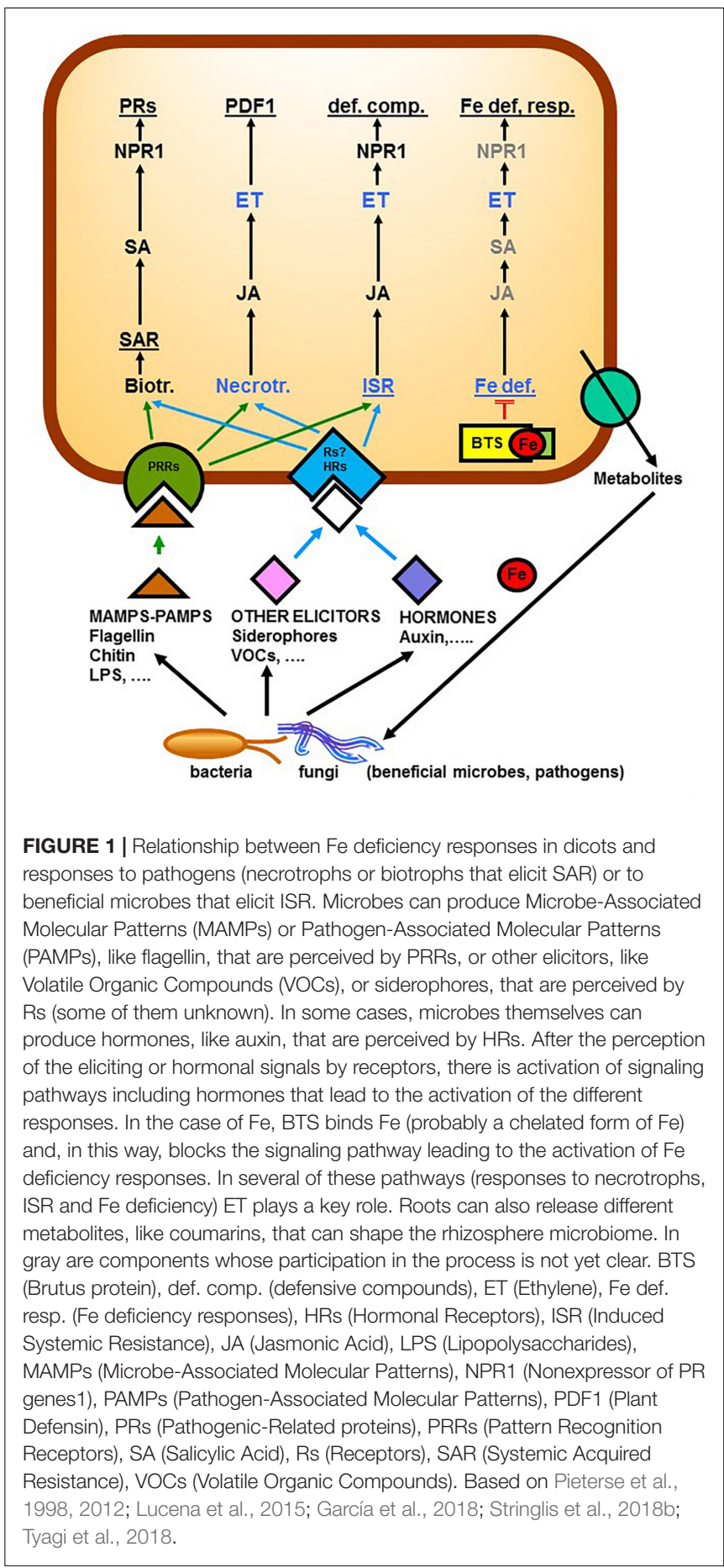

\section{How Is ISR Triggered by Beneficial Rhizosphere Microbes?}

The ways beneficial rhizosphere microbes elicit ISR are not totally understood but several microbial elicitors have been proposed to be responsible for its onset. These elicitors, upon perception, would trigger the ISR through the action of diverse plant hormones (Figure 1; Pieterse et al., 2012, 2014; Sharifi and Ryu, 2018; Tyagi et al., 2018). Among these elicitors, 
there are Microbe-Associated Molecular Patterns (MAMPs) and other elicitors, like Volatile Organic Compounds (VOCs) or siderophores (Figure 1; Zhang et al., 2007, 2009; Jankiewicz and Koltonowicz, 2012; Orozco-Mosqueda et al., 2013; Pieterse et al., 2014; Zamioudis et al., 2015; Garnica-Vergara et al., 2016; Martínez-Medina et al., 2017; Sharifi and Ryu, 2018; Tyagi et al., 2018; Villena et al., 2018). MAMPs (when produced by pathogens are named Pathogen-Associated Molecular Patterns: PAMPs) are conserved microbial molecules released by the microbes, like flagellin, chitin, and lipopolysaccharides (LPS; Zeidler et al., 2004; Pieterse et al., 2014; Villena et al., 2018). VOCs are low molecular weight compounds derived from different biosynthetic pathways, with high vapor pressure and that can evaporate and disperse easily (Sharifi and Ryu, 2018; Tyagi et al., 2018). At present, over 1000 volatile compounds (including alkanes, alcohols, esters, ketones, sulfides, terpenoids, and sesquiterpenes) have been identified (Tyagi et al., 2018). Those derived from beneficial microbes can trigger drastic changes in plant growth patterns, generally by altering hormone signaling (Garnica-Vergara et al., 2016; Martínez-Medina et al., 2017; Sharifi and Ryu, 2018; Tyagi et al., 2018). Siderophores are Fe chelating agents released by the bacteria to further acquire Fe from the medium (Lemanceau et al., 2009; Aznar and Dellagi, 2015; Aznar et al., 2014, 2015).

Microbe-Associated Molecular Patterns are perceived by Pattern Recognition Receptors (PRRs) while other elicitors could be perceived by other Receptors (Rs), not known in all cases (Figure 1; Jankiewicz and Koltonowicz, 2012; Pieterse et al., 2014; Aznar and Dellagi, 2015; Aznar et al., 2015; Sharifi and Ryu, 2018; Tyagi et al., 2018; Villena et al., 2018). Upon perception, the elicitors trigger the ISR by affecting diverse plant hormones that act as central players in the plant immune signaling network leading to the activation of the defense responses (Figure 1; Pieterse et al., 2012, 2014; Sharifi and Ryu, 2018; Tyagi et al., 2018). In some cases, the microbes themselves can also produce different hormones, like auxin or cytokinins, that upon perception by the plant hormonal receptors (HRs) can cause changes in the root physiology and morphology (Grady et al., 2016; Scagliola et al., 2016; Asari et al., 2017; Kudoyarova et al., 2017; Patel and Saraf, 2017). Among the hormones implicated in the ISR, JA, ET, auxin, and NO play a key role (Knoester et al., 1999; Ton et al., 2001; Shoresh et al., 2005; Zhang et al., 2007; Van der Ent et al., 2008; Camehl et al., 2010; Acharya et al., 2011; Pieterse et al., 2014; Garnica-Vergara et al., 2016; Hossain et al., 2017; Martínez-Medina et al., 2017; Nie et al., 2017; Nascimento et al., 2018; Stringlis et al., 2018a).

\section{ISR Characteristics}

One general characteristic of the microbial elicitors that induce ISR is their redundancy. This redundancy implies that microbial mutants defective in one elicitor can induce ISR through other elicitors (Meziane et al., 2005; Pieterse et al., 2014; Zamioudis et al., 2015). For example, the siderophore pseudobactin was as effective in inducing ISR as live bacteria but a mutant defective in pseudobactin biosynthesis was equally effective (Meziane et al., 2005). Beneficial ISR-eliciting microbes do not directly activate defense responses but sensitize the whole plant (a phenomenon called priming) for a faster and stronger activation of defense responses upon invasion by pathogens (Choudhary et al., 2007; Berendsen et al., 2012; Jung et al., 2012; Pieterse et al., 2014; Martinez-Medina et al., 2016). A high percentage of the genes, predominantly associated with defense responses, induced by the elicitors, like flagellin, are suppressed by the ISR-eliciting microbes to allow the establishment of a mutually beneficial interaction with the host root (Stringlis et al., 2018a). There is increasing evidence that beneficial soil-borne microbes hijack plant hormone signaling pathways to suppress the host defenses (Pieterse et al., 2012). This is also the case for the symbiotic relationship between legumes and rhizobia where the defense reactions set up by the plant are quickly suppressed, allowing microbial entry and the potential successful rhizobial establishment in plant roots (Guinel, 2015).

To elicit ISR, beneficial rhizobacteria must reach a minimal concentration equal to $10^{5}-10^{7}$ colony forming unit (CFU) per gram of root for several days (Jankiewicz and Koltonowicz, 2012; Bakker et al., 2013; Pieterse et al., 2014). It should be noted that in the rhizosphere, the microbial density can range from $10^{8}$ to $10^{9}$ bacteria per gram and that its diversity is generally less than in the bulk soil since plant exudates specifically stimulate or repress members of the microbial community shaping the root microbiome (Figure 1; Berendsen et al., 2012; Bakker et al., 2013; Pii et al., 2016a; Stringlis et al., 2018b). In this sense, very recently it has been found that the release of the antimicrobial coumarin scopoletin by roots of Arabidopsis plants inoculated with the rhizobacterium $P$. simiae inhibits some soil-borne pathogens but not the rhizobacterium (Stringlis et al., 2018b). Coumarins are phenolic compounds that are also released by Fe-deficient roots to favor the Fe acquisition of plants (Schmid et al., 2014; Schmidt et al., 2014; Tsai and Schmidt, 2017a; Siwinska et al., 2018; Tsai et al., 2018; see also Section "Fe deficiency responses in dicot plants"). Consequently, the ISR-eliciting microbes, by inducing the release of coumarins and other Fe deficiency responses in plants, can improve the Fe nutrition of plants but, at the same time, they can benefit from a niche where their competitors are eliminated or restricted (Stringlis et al., 2018b).

\section{INTERRELATIONSHIP BETWEEN ISR AND Fe DEFICIENCY RESPONSES IN DICOT PLANTS}

Since $\mathrm{Fe}$ acquisition is a limiting factor in most soils, $\mathrm{Fe}$ is a central player in the tripartite interaction among beneficial microbes, pathogens, and plants (López-Berges et al., 2013; Naranjo-Arcos and Bauer, 2016; Verbon et al., 2017). This close interrelation is in good agreement with the already described relationship between $\mathrm{Fe}$ homeostasis and defense responses against pathogens in plants (Lemanceau et al., 2009; Aznar et al., 2015; Verbon et al., 2017) and with the crosstalk between ISR and Fe deficiency responses (Pieterse et al., 2014; Verbon et al., 2017). The relationship between plant defense responses and Fe deficiency is complex and depends on several factors, like the plant genotype, the kind of pathogens and the intensity and duration of the deficiency. In some cases, plants are more tolerant to pathogens under conditions of Fe deficiency, 
TABLE 1 | Microbial species that induce Fe deficiency responses when applied to dicot plants.

\begin{tabular}{|c|c|c|c|c|c|c|c|}
\hline Microbial species & Plant species & $\begin{array}{l}\text { Mode } \\
\text { appl. }\end{array}$ & Signals & Fe def. resp. & Fe genes & Fe Gr. & Refs \\
\hline \multicolumn{8}{|l|}{ Rhizobacteria } \\
\hline Azospirillum brasilense & Solanum lycopersicum & $\operatorname{gm}(\mathrm{a})$ & ET Auxin & Root hairs & nd & $\wedge$ & Ribaudo et al., 2006 \\
\hline Azospirillum brasilense & Cucumis sativus & gm(ns) & nd & $\mathrm{FCR}, \mathrm{pH}$ & FIT FRO1 IRT1 HA1 & $\mathrm{Fe}$ & Pii et al., 2016b \\
\hline Bacillus subtilis & Arabidopsis thaliana & $\operatorname{gm}(\mathrm{a})$ & VOCs & $\mathrm{FCR}, \mathrm{pH}$ & FIT FRO2 IRT1 & $\mathrm{Fe}$ & Zhang et al., 2009 \\
\hline Arthrobacter agilis* & Medicago truncatula & $\operatorname{gm}(a)$ & VOCs & $\mathrm{FCR}, \mathrm{pH}$ & nd & $\mathrm{Fe} \wedge$ & $\begin{array}{l}\text { Orozco-Mosqueda } \\
\text { et al., } 2013\end{array}$ \\
\hline Pseudomonas simiae & Arabidopsis thaliana & $\operatorname{gm}(a)$ & $\begin{array}{l}\text { VOCs Auxin } \\
\text { NO }\end{array}$ & FCR phenolics & $\begin{array}{l}\text { FIT FRO2 bHLH38 } \\
\text { bHLH39 IRT1 F6' H1 } \\
\text { MYB72 BGLU42 } \\
\text { ABCG37 }\end{array}$ & & $\begin{array}{l}\text { Zamioudis et al., 2014, } \\
\text { 2015; Stringlis et al., } \\
\text { 2018b }\end{array}$ \\
\hline $\begin{array}{l}\text { Enterobacter* } \\
\text { Pseudomonas }\end{array}$ & Cucumis sativus & gm(ns) & Auxin & FCR & nd & nd & Scagliola et al., 2016 \\
\hline Paenibacillus polymyxa & Arabidopsis thaliana & $\operatorname{gm}(\mathrm{a})$ & Auxin & FCR, pH, phenolics & $\begin{array}{l}\text { FIT FRO2 IRT1 } \\
\text { MYB72 F6'H1 }\end{array}$ & $\mathrm{Fe} \wedge$ & Zhou et al., 2016a \\
\hline Bacillus amyloliquefaciens & Arabidopsis thaliana & $\operatorname{gm}(\mathrm{a})$ & $\begin{array}{l}\text { VOCs Auxin } \\
\text { NO }\end{array}$ & FCR & FIT FRO2 IRT1 & $\mathrm{Fe} \wedge$ & $\begin{array}{l}\text { Wang J. et al., 2017; } \\
\text { Zhou et al., } 2017\end{array}$ \\
\hline Burkholderia cepacia & Astragalus sinicus & ri(s) & Auxin & FCR, pH, flavins & FIT FRO2 IRT1 AHA2 & $\mathrm{Fe} \wedge$ & Zhou et al., 2018 \\
\hline \multicolumn{8}{|l|}{ Rhizofungi } \\
\hline Trichoderma asperellum & Cucumis sativus & $g m(s)$ & nd & FCR & nd & $\mathrm{Fe} \wedge$ & Zhao et al., 2014 \\
\hline $\begin{array}{l}\text { Trichoderma asperellum, } \\
\text { T. harzianum }\end{array}$ & Arabidopsis thaliana & gm(a) & VOCs & FCR, root hairs & $\begin{array}{l}\text { FIT FRO2 bHLH38 } \\
\text { bHLH39 IRT1 MYB72 }\end{array}$ & nd & $\begin{array}{l}\text { Martínez-Medina et al., } \\
2017\end{array}$ \\
\hline $\begin{array}{l}\text { Trichoderma asperellum, } \\
\text { T. harzianum }\end{array}$ & Solanum lycopersicum & $\operatorname{gm}(\mathrm{a})$ & VOCs & FCR, root hairs & FER FRO1 IRT1 & nd & $\begin{array}{l}\text { Martínez-Medina et al., } \\
2017\end{array}$ \\
\hline
\end{tabular}

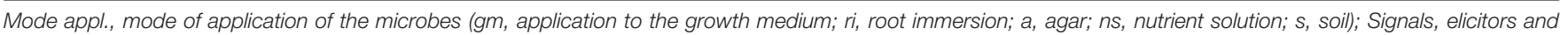

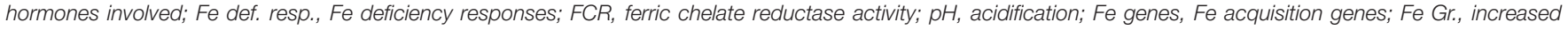
shoot Fe concentration (Fe) and increased shoot growth $(\wedge)$; nd, not determined; *, microbial species whose association with ISR is not yet clear.

probably because pathogens require an adequate quantity of Fe for full virulence (Kieu et al., 2012; López-Berges et al., 2013). However, in other cases, plants are more susceptible to pathogens under Fe-deficient conditions (Verbon et al., 2017 and references therein). The competition for Fe between soilborne pathogens and their antagonistic microorganisms has been related to disease suppression; siderophores produced in the rhizosphere by PGPR can inhibit growth of the pathogens by depriving them of Fe (Verbon et al., 2017). In contrast to the negative effect of some soil-borne pathogens on Fe acquisition, there are several recent reviews showing an important role of beneficial rhizosphere microbes on the Fe nutrition of plants (Jin et al., 2014; Mimmo et al., 2014; Pii et al., 2015; İpek and Esitken, 2017). These microbes can directly improve Fe nutrition through the release of $\mathrm{H}^{+}$and/or $\mathrm{Fe}$ - solubilizing compounds to soils, like siderophores and organic acids, or by inducing changes in root physiology and architecture, which can improve the acquisition of $\mathrm{Fe}$ and also of other nutrients (Orozco-Mosqueda et al., 2013; Jin et al., 2014; Mimmo et al., 2014; Zhao et al., 2014; Contreras-Cornejo et al., 2015; Pii et al., 2015, 2016b; Garnica-Vergara et al., 2016; Scagliola et al., 2016; Verbon and Liberman, 2016; Zhou et al., 2016a,b; MartínezMedina et al., 2017; Sonbarse et al., 2017; Sharifi and Ryu, 2018; Stringlis et al., 2018a). In this way, it has been demonstrated that ISR-eliciting microbes can induce Fe deficiency responses in their host roots, such as enhanced ferric reductase activity, acidification of the rhizosphere, release of phenolics and flavins, and development of root hairs; and the expression of the genes associated with these responses, such as FIT, bHLH38, bHLH39, MYB72, MYB10, FRO2, IRT1, AHA, F6'H1, BGLU42, ABCG37, and others (Figures 1, 2 and Table 1; Ribaudo et al., 2006; Zhang et al., 2009; Zamioudis et al., 2014, 2015; Zhao et al., 2014; Pii et al., 2016b; Scagliola et al., 2016; Verbon and Liberman, 2016; Zhou et al., 2016a,b, 2018; Martínez-Medina et al., 2017; Verbon et al., 2017; see also Section "Fe deficiency responses in dicot plants" and Section "Rhizosphere microbial species that induce Fe deficiency responses and improve Fe acquisition").

Since bacteria that elicit ISR can release siderophores to the medium, it has been speculated that perhaps these $\mathrm{Fe}$ chelating agents could deprive plants of $\mathrm{Fe}$ and in this way cause the induction of Fe deficiency responses (Van der Ent, 2008; Aznar et al., 2014; Pieterse et al., 2014; Aznar and Dellagi, 2015; Zamioudis et al., 2015). However, mutants defective in siderophore biosynthesis also induce Fe deficiency responses, which suggests that they could induce these responses through other mechanisms (Meziane et al., 2005; Pieterse et al., 2014; Zamioudis et al., 2015). A possibility could be through alteration of hormone biosynthesis and signaling in the plants. In this sense, the plant hormone ET has been implicated in both the activation of ISR (Knoester et al., 1999; Ton et al., 2001; Shoresh et al., 2005; Camehl et al., 2010; Pieterse et al., 2012; GarnicaVergara et al., 2016; Hossain et al., 2017; Nie et al., 2017) and the activation of Fe deficiency responses (Figures 1, 2; reviewed in Lucena et al., 2015; Li and Lan, 2017; Romera et al., 2017). Besides 


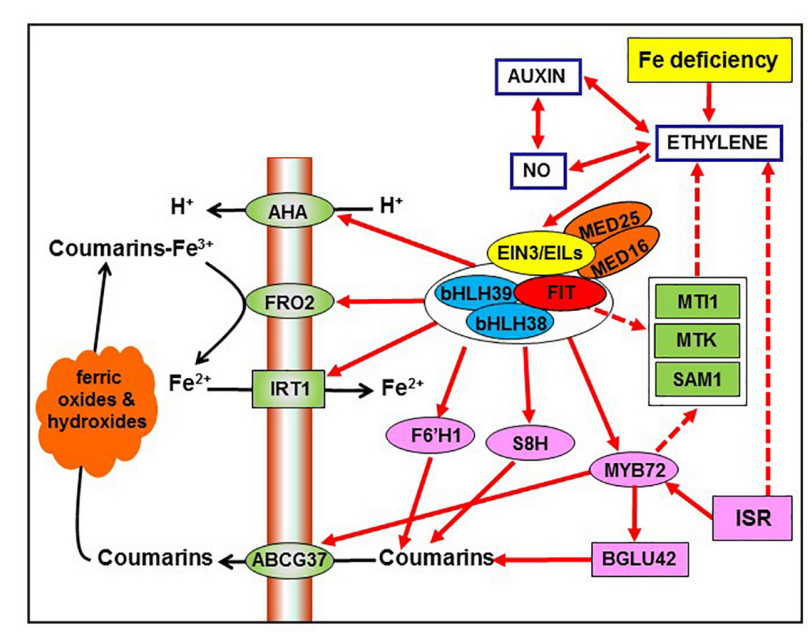

FIGURE 2 | Possible interrelationship between ISR and Fe deficiency responses through the common participation of ethylene in both processes (see Figure 1). Ethylene, through the activation of the transcription factors FIT, $\mathrm{bHLH} 38$, and bHLH39, can up-regulate the expression of several genes associated with Fe deficiency, like AHA, FRO2, IRT1, FG'H1, and S8H. Additionally, FIT/bHLH38/bHLH39 can up-regulate the expression of MYB72, which activates the $\beta$-glucosidase BGLU42 and the phenolic efflux transporter ABCG37, both being implicated in the secretion of phenolic compounds, like coumarins. Moreover, FIT and MYB72 could indirectly act by affecting ethylene synthesis, through the upregulation of SAM1, MTK, and MTI1.

Besides ethylene, auxin, and nitric oxide (NO) can also affect these Fe-related genes since they are closely interrelated with ethylene. Based on Lucena et al. (2015). For more details, see Section "Interrelationship between ISR and Fe deficiency responses."

ET, other hormones and signaling molecules, like auxin, and NO, have also been implicated in both processes (García et al., 2010; Acharya et al., 2011; Romera et al., 2011, 2017; Zamioudis, 2012; Jin et al., 2014; Contreras-Cornejo et al., 2015; Garnica-Vergara et al., 2016; Poupin et al., 2016; Stringlis et al., 2018a). Moreover, the root-specific MYB72 TF, that plays a key role in the onset of ISR (Van der Ent et al., 2008; Segarra et al., 2009; Zamioudis et al., 2014; Verbon et al., 2017; Stringlis et al., 2018b), is also essential for plant growth on low Fe conditions (Figure 2; García et al., 2011; Palmer et al., 2013; Zamioudis et al., 2014, 2015; Lucena et al., 2015; Verbon et al., 2017; see also Section "Fe deficiency responses in dicot plants"). This indicates that MYB72 is a node of convergence between ISR and Fe deficiency responses (Van der Ent et al., 2008; Segarra et al., 2009; Pieterse et al., 2014; Zamioudis et al., 2014, 2015; Verbon et al., 2017). All these results suggest that the regulatory pathways of ISR and Fe deficiency responses overlap. In the following paragraphs the main common components shared by ISR and Fe deficiency responses are described and analyzed.

\section{Ethylene and Other Hormones and Signaling Molecules}

As previously stated (see Section "Induced Systemic Resistance"), ISR is generally mediated by a pathway where JA and ET are the central players (Figure 1; Pieterse et al., 1998, 2002,
2012, 2014; Van Loon et al., 1998; Choudhary et al., 2007). In this pathway, JA acts upstream of ET, and ET upstream of the NPR1 protein (Figure 1; Pieterse et al., 1998, 2002, 2012, 2014; Van Loon et al., 1998; Choudhary et al., 2007). NPR1 functions in the nucleus as a transcriptional coactivator of SA-responsive genes during the SAR pathway, but NPR1 also plays a cytosolic function in the JA/ET signaling during the ISR pathway (Figure 1; Pieterse et al., 2014). In relation to these components (ET, JA, SA, and NPR1), ET has been clearly implicated in the regulation of Fe deficiency responses in Strategy I plants and in rice, that presents characteristics of both Strategy I and II plant species (reviewed in Lucena et al., 2015; Li and Lan, 2017; Romera et al., 2017). However, the roles of the other components (JA, SA, and NPR1) on Fe deficiency responses are not yet clear. For instance, JA has been implicated in the regulation of Fe deficiency responses in Strategy I plants but as a suppressor of these responses (Maurer et al., 2011). In rice, JA has been shown to activate the expression of some $\mathrm{Fe}$ deficiency responses at the very early stages of the Fe deficiency (0.5-1 h) but strongly suppresses them later on (3-6 h; Kobayashi et al., 2016). In relation to the role of SA on the regulation of Fe deficiency responses, the results are contrasting. It was shown that Arabidopsis lines overexpressing the SA-inducible transcription factor OBF-BINDING PROTEIN 3 (OBP3) present upregulation of $b H L H 038$ and $b H L H 039$, encoding two TFs that play a key role in the activation of $\mathrm{Fe}$ acquisition genes (Kang et al., 2003; see Section "Fe deficiency responses in dicot plants"). In the same way, exogenous application of SA to Arabidopsis plants upregulates the expression of YELLOW STRIPE-LIKE1 (YSL1) and YSL3, which are involved in Fe translocation and homeostasis (Chen et al., 2014; Kumar et al., 2017). Shen et al. (2016) further found that Fe deficiency increases SA contents in shoots and roots of Arabidopsis plants, and that the SA biosynthesis defective mutant phytoalexin deficient 4 (pad4) presents altered Fe deficiency responses, suggesting a link between SA and Fe deficiency. However, Maurer et al. (2014) found that SA and SA signaling through NPR1 (Figure 1) do not affect $\mathrm{Fe}$ deficiency responses. To complete this network of interactions, some Fe-related TFs, such as ILR3 (bHLH105; belonging to the IVc bHLH subgroup; Zhang et al., 2015; see also Section "Fe deficiency responses in dicot plants"), can affect JA and SA biosynthesis (Aparicio and Pallás, 2017). After analyzing all these results, it is clear that the role of JA and SA on the regulation of Fe deficiency responses in dicots deserves further research.

In relation to ET, this plant hormone is synthetized from the amino acid methionine, through a pathway requiring SAMS (S-adenosyl methionine synthetase), ACS [1-aminocyclopropane1-carboxylic acid (ACC) synthase], and ACO (ACC oxidase; Sauter et al., 2013; Wang F. et al., 2013; Dubois et al., 2018):

$$
\begin{gathered}
\text { SAMS ACS ACO } \\
\text { Methionine } \rightarrow \text { SAM } \rightarrow \text { ACC } \rightarrow \text { Ethylene }
\end{gathered}
$$

Although ET's mode of action is not fully understood, a linear signaling pathway has been proposed in Arabidopsis 
(Shakeel et al., 2013; Wang F. et al., 2013; Dubois et al., 2018):

$$
\begin{aligned}
& \text { ET } \rightarrow \text { ET receptors } \rightarrow \text { CTR1 }-\| \text { EIN2 } \rightarrow \text { EIN3/EILs } \\
& \quad \rightarrow \text { ERFs } \rightarrow \text { ET responses }
\end{aligned}
$$

In this signaling pathway, all the components are proteins and, within them, EIN3/EILs and ERFs are TFs (for more details, see Shakeel et al., 2013; Wang F. et al., 2013; Lucena et al., 2015; Dubois et al., 2018).

The participation of ET in the regulation of Fe deficiency responses was first proposed by Romera and Alcántara (1994) and has been further supported by many experimental data (recently reviewed in Lucena et al., 2015; Li and Lan, 2017; Romera et al., 2017). As more recent evidence, it should be mentioned that FIT (master regulator of $\mathrm{Fe}$ acquisition genes in Arabidopsis; see Section "Fe deficiency responses in dicot plants") interacts with the EIN3 and EIL1 TFs, associated with ET signaling, and with MED16 and MED25, Mediators, to form a complex implicated in the transcription of $\mathrm{Fe}$ acquisition genes (Figure 2; Lingam et al., 2011; Yang et al., 2014; Brumbarova et al., 2015). In the same way, recently it has been found that the ERF4 and ERF72 TFs, that are also associated with ET signaling, are induced under Fe deficiency and participate in the regulation of Fe deficiency responses (Liu et al., 2017a,b). Fe deficiency causes the upregulation of genes involved in both ET synthesis, like SAM, ACS, ACO, MTK, MTI1, MPK3, and MPK6, and signaling, like EIN2, EIN3, EIL1, EIL3,ERF4, and ERF72, in roots of different dicot plants (García et al., 2010; Ye et al., 2015; Li and Lan, 2017; Romera et al., 2017). MTK (5-methylthioribose kinase) and MTI1 (5-methylthioribose-1phosphate isomerase1) participate in the Yang cycle and are necessary for ET biosynthesis (Pommerrenig et al., 2011; Sauter et al., 2013). Both MTK and MTI1, besides their upregulation under Fe deficiency, are also regulated by ET, probably through FIT (Figure 2; Colangelo and Guerinot, 2004; García et al., 2010). MTI1 (At2g05830) was previously identified as eIF-2B, a putative eukaryotic translation initiation factor (García et al., 2010; Pommerrenig et al., 2011). The mitogen-activated protein kinases 3 and 6 (MPK3/MPK6) are related to ET (Li et al., 2012; Contreras-Cornejo et al., 2015; Dubois et al., 2018) and can activate ACS2/6 in Fe deficiency-induced ET production (Ye et al., 2015).

Ethylene has been involved in the regulation of both morphological and physiological responses to Fe deficiency in Strategy I plants (Romera and Alcántara, 1994, 2004; Lucena et al., 2015; Li and Lan, 2017; Romera et al., 2017). In relation to the morphological responses, ET has been implicated in the formation of subapical root hairs, cluster roots, and transfer cells (reviewed in Lucena et al., 2015). In relation to the physiological responses, ET has been implicated in the upregulation of FIT (or its tomato homolog FER), bHLH38, bHLH39, and MYB72, encoding key TFs (Figure 2; Lucena et al., 2006; García et al., 2010; Lingam et al., 2011). bHLH38 and bHLH39 interact with FIT to form heterodimers that activate the expression of the Fe acquisition genes FRO2 (ferric reductase) and IRT1 (iron transporter) (Figure 2; Yuan et al., 2008; Wang N. et al., 2013). Similarly, the acidification capacity, depending on AHA-like genes (Colangelo and Guerinot, 2004), is also activated by FIT and consequently by ET (Figure 2; Waters et al., 2007; Lucena et al., 2015). In relation to the excretion of phenolics, it has been found that the expression of $F 6^{\prime} \mathrm{H} 1$ and $S 8 \mathrm{H}$, involved in their synthesis, is dependent on FIT (Figure 2; García et al., 2010; Schmid et al., 2014; Tsai and Schmidt, 2017a; Tsai et al., 2018; see also "Fe deficiency responses in dicots"). Consequently, both of them would also be dependent on ET (Figure 2). In supporting this view, $\mathrm{S} 8 \mathrm{H}$ (At3g12900) is greatly induced in Fe deficient roots and drastically inhibited by ethylene inhibitors (García et al., 2010). Besides all the above genes related to Fe acquisition, ET also participates in the activation of NAS1 (nicotianamine synthase1), NAS2, and FRD3 (ferric reductase defective3), that are very important for internal Fe mobilization and homeostasis (García et al., 2010).

Besides its involvement in Fe deficiency responses, ET has also been implicated in the development of ISR triggered by root-colonizing microbes, acting downstream of JA (Figure 1; Knoester et al., 1999; Ton et al., 2001; Shoresh et al., 2005; Ribaudo et al., 2006; Van Loon et al., 2006; Van der Ent, 2008; Camehl et al., 2010; Pieterse et al., 2012; Zamioudis, 2012; Contreras-Cornejo et al., 2015; Garnica-Vergara et al., 2016; Hossain et al., 2017; Nie et al., 2017; Nascimento et al., 2018). In general, root colonization by ISR-eliciting microbes does not induce a direct enhancement of ET and JA biosynthesis (Knoester et al., 1999; Pieterse et al., 2014) except in some cases (Ribaudo et al., 2006; Contreras-Cornejo et al., 2015). However, the expression of genes involved in ET biosynthesis, like ACSs and ACOs, and signaling, like ETR1, EIL3, CTR1, and $E R F s$, is frequently upregulated in roots by ISR-eliciting microbes (Shoresh et al., 2005; Ribaudo et al., 2006; Van der Ent et al., 2008; Velivelli et al., 2015; Zamioudis et al., 2015; Poupin et al., 2016). For example, root colonization by P. simiae WCS417 induced the upregulation of ACS2, ACS6, and EIL3 in Arabidopsis roots (Van der Ent et al., 2008; Zamioudis et al., 2015), which are also upregulated under Fe deficiency (García et al., 2010; Ye et al., 2015).

In both processes, ISR and Fe deficiency responses, ET can have a dual role. It is necessary for the activation of $\mathrm{Fe}$ deficiency responses (Lucena et al., 2015; Li and Lan, 2017; Romera et al., 2017) and for the onset of ISR (Knoester et al., 1999; Ton et al., 2001; Shoresh et al., 2005; Ribaudo et al., 2006; Pieterse et al., 2012, 2014; Garnica-Vergara et al., 2016; Hossain et al., 2017; Nie et al., 2017; Nascimento et al., 2018). However, when accumulated in excess, ET can have negative effects on the responses to Fe deficiency (Romera et al., 1999), on the growth of plants and on the mutualistic interactions with beneficial microbes (Pierik et al., 2007; Camehl et al., 2010; Gamalero and Glick, 2015; Nascimento et al., 2018). This dual role also occurs for the nodulation between legumes and rhizobia, where ET is crucial for the proper development of the rhizobial colonization but also acts as a negative regulator to limit the number of rhizobial infections (Zamioudis, 2012; Guinel, 2015). To avoid the detrimental effects of ET, some beneficial microbes and plant species possess the enzyme ACC deaminase, that eliminates the ET 
precursor ACC (Gamalero and Glick, 2015; Singh et al., 2015; Nascimento et al., 2018).

The participation of ET on morphological and physiological responses to Fe deficiency and on ISR probably follows different ET signaling pathways. While several Arabidopsis ethylene insensitive mutants, like etr1, ein 2 , ein 3 , and eir1, are blocked in their capacity to mount the ISR (Knoester et al., 1999; Ton et al., 2001; Van Loon et al., 2006; Camehl et al., 2010; Zamioudis, 2012; Alizadeh et al., 2013; Contreras-Cornejo et al., 2015; Hossain et al., 2017; Nie et al., 2017), and to develop morphological responses to Fe deficiency (Romera and Alcántara, 2004), they can induce most of the physiological responses to Fe deficiency (Romera and Alcántara, 2004; Lucena et al., 2006; García et al., 2010). These differences are perhaps related to the existence of an alternate route for ethylene signaling, besides the conventional one that includes EIN2 (see above; Shakeel et al., 2013). At this point, it has been suggested that for several physiological responses, ET could act through a pathway where EIN2 is not strictly required (Lucena et al., 2015).

Besides ET, other hormones and signaling molecules, such as auxin, GSH and NO have also been involved in both ISR and Fe deficiency responses (Ribaudo et al., 2006; Graziano and Lamattina, 2007; Bacaicoa et al., 2009, 2011; Chen et al., 2010; García et al., 2010, 2011, 2018; Acharya et al., 2011; Romera et al., 2011, 2017; Jin et al., 2014; Contreras-Cornejo et al., 2015; Shanmugam et al., 2015; Zamioudis et al., 2015; GarnicaVergara et al., 2016; Poupin et al., 2016; Zhou et al., 2016a, 2017, 2018; Wang J. et al., 2017; Gullner et al., 2018; Kailasam et al., 2018; Sharifi and Ryu, 2018; Stringlis et al., 2018a; Sumayo et al., 2018; Tyagi et al., 2018). All of them increase in roots under Fe deficiency and frequently upon colonization of roots by ISR-eliciting microbes (Romera et al., 1999; Ribaudo et al., 2006; Graziano and Lamattina, 2007; Bacaicoa et al., 2009, 2011; Chen et al., 2010; Contreras-Cornejo et al., 2015; Shanmugam et al., 2015; Zamioudis et al., 2015; Zhou et al., 2016a, 2017; Wang J. et al., 2017; Kailasam et al., 2018). Some microbial elicitors, like VOCs or LPS, can affect ET, auxin or NO production and/or signaling, and in this way upregulate Fe-related genes (Zeidler et al., 2004; Zhang et al., 2007, 2009; Kwon et al., 2010; Liu and Zhang, 2015; Zamioudis et al., 2015; GarnicaVergara et al., 2016; Zhou et al., 2017; Wang J. et al., 2017; Sharifi and Ryu, 2018; Tyagi et al., 2018). As examples, VOCs from Bacillus subtilis GB03 upregulated the expression of several ET biosynthesis genes (Kwon et al., 2010) and VOCs from P. simiae WCS417 or Bacillus amyloliquefaciens BF06 caused NO accumulation in Arabidopsis roots and upregulated several Fe-related genes (Zamioudis et al., 2015; Wang J. et al., 2017). Moreover, some of these hormones and signaling molecules can affect the perception of microbial elicitors. For example, the PRR for flagellin (FLAGELLIN-SENSING 2-FLS2) is regulated by ET (Boutrot et al., 2010).

Ethylene, auxin, and NO are closely interrelated since each one can affect the synthesis and/or action of the others (Figure 2; Ribaudo et al., 2006; Chen et al., 2010; García et al., 2011, 2018; Romera et al., 2011, 2017; Contreras-Cornejo et al., 2015; Garnica-Vergara et al., 2016; Poupin et al., 2016; Zhou et al., 2017). As a probe of their close interrelationship, FIT,
MYB72, and other Fe- and ISR-related genes are similarly affected by ET, auxin, or NO treatments. They are upregulated by these molecules, or their precursors, and downregulated by their inhibitors (Graziano and Lamattina, 2007; Chen et al., 2010; García et al., 2010, 2011; Zamioudis et al., 2015; Wang J. et al., 2017; Zhou et al., 2017; Stringlis et al., 2018a; Sumayo et al., 2018).

In the last years, the roles of GSH and $\mathrm{NO}$ in the activation of responses to Fe deficiency are becoming more complex since several experimental results have shown that $S$-nitrosoglutathione (GSNO), derived from GSH and NO, specifically works in such an activation having a different role that the one of NO (García et al., 2018; Kailasam et al., 2018). $\mathrm{NO}, \mathrm{GSH}$, and GSNO have also been implicated in plant defense responses against pathogens, and NO and GSH in ISR (Zamioudis et al., 2015; Yun et al., 2016; Gullner et al., 2017, 2018). Moreover, in plant defense responses, NO and GSNO exhibit additive functions and, by extension, may have distinct or overlapping molecular targets (Yun et al., 2016). The roles of GSH and GSNO in these processes have been related to their capacity to detoxify toxins (by their conjugation with $\mathrm{GSH}$ ), to their interconnection with reactive oxygen species and SA, and to their capacity to modulate the redox state of NPR1 and to $S$-nitrosylate defense-related TFs and transcriptional coregulators (Yun et al., 2016; Gullner et al., 2017, 2018). However, to our knowledge, only NO has been implicated in the signaling processes leading to the activation of Fe acquisition genes by ISR-eliciting microbes (Zamioudis et al., 2015) while GSH and GSNO have not yet been studied in relation to this activation, which deserves further research.

\section{MYB72 and Other Transcription Factors}

Some years ago, it was found that the MYB72 gene, encoding a TF, was greatly induced in Arabidopsis roots under $\mathrm{Fe}$ deficiency (Colangelo and Guerinot, 2004) and also upon their colonization with the ISR-eliciting rhizobacterium $P$. simiae WCS417 (Verhagen et al., 2004; Van der Ent, 2008; Van der Ent et al., 2008). Later on, MYB72 upregulation has also been demonstrated with other ISR-eliciting microbes (Segarra et al., 2009; Alizadeh et al., 2013; Pieterse et al., 2014; Martínez-Medina et al., 2017; Verbon et al., 2017). Furthermore, Arabidopsis myb72 knockout mutants are defective in the activation of ISR which suggests that MYB72 plays a key role in the early signaling steps of this process (Figure 2; Van der Ent, 2008; Van der Ent et al., 2008; Segarra et al., 2009; Alizadeh et al., 2013; Zamioudis et al., 2014, 2015; Stringlis et al., 2018b). However, overexpression of MYB72 did not result in enhanced resistance against any of the pathogens tested, demonstrating that MYB72 is not sufficient for the expression of ISR (Van der Ent et al., 2008). In both Fe deficiency and ISR, MYB72 is upregulated along with MYB10, also encoding a TF (Colangelo and Guerinot, 2004; Zamioudis, 2012; Palmer et al., 2013; Zamioudis et al., 2015). MYB72 and MYB10 physically interact in vivo and function redundantly in regulating the expression of genes involved in the shikimate, the phenylpropanoid and the nicotianamine (NA) biosynthesis pathways (Zamioudis, 2012; Zamioudis et al., 2014, 2015; Stringlis et al., 2018b). Under 
Fe deficiency, both MYB72 and MYB10 act early in the Fe deficiency regulatory cascade to drive gene expression of NAS2 and NAS4, two NA synthase genes (Palmer et al., 2013). An important difference of the participation of MYB72 and MYB10 in ISR and Fe deficiency responses is that the Arabidopsis myb72 mutants are defective in the activation of ISR (see above) while they behave apparently normal when grown on alkaline soil, a condition that favors Fe deficiency (Palmer et al., 2013). However, the myb10myb72 double mutant displays seedling lethality when grown on alkaline soil (Palmer et al., 2013). This suggests that MYB10 and MYB72 have overlapping roles in relation to Fe deficiency (Palmer et al., 2013). In relation to ISR, MYB72, and MYB10 coordinately suppress the expression of a large group of defense-related genes upon root colonization by $P$. simiae WCS417, enabling the bacteria to establish long-term associations with host roots (Zamioudis, 2012). The bacteria can also colonize roots of the myb72 mutant (Van der Ent et al., 2008), suggesting that MYB10 may compensate in defense suppression (Zamioudis, 2012).

MYB72 is consequently a node of convergence between ISR and Fe deficiency responses in dicots. This convergence is further supported when considering that MYB72 expression is controlled by FIT either under Fe deficiency or upon colonization of roots by ISR-eliciting microbes (Figure 2; Colangelo and Guerinot, 2004; Sivitz et al., 2012; Palmer et al., 2013; Zamioudis et al., 2015). Moreover, FIT interacts with the bHLH38 TF to control MYB72 expression upon colonization of roots by ISR-eliciting microbes (Zamioudis et al., 2015), as occurred with FRO2 and IRT1 expression under Fe deficiency (Yuan et al., 2008). FIT, bHLH38, and MYB72 expression is activated by ET (García et al., 2010, 2011), which suggests a connection between the regulation of $\mathrm{Fe}$ deficiency responses and ISR through this plant hormone. In supporting this view, several $P$. simiae WCS417-inducible MYB72 target genes, like BGLU42 ( $\beta$-glucosidase), CYP71B5 (cytochrome P450), At5g55620 (unknown function), and bHLH39 (TF), are all induced by Fe deficiency and also activated by ET (García et al., 2010; Zamioudis et al., 2014). Moreover, MYB72 and BGLU42 present ET-responsive elements in their promoters (García et al., 2010). Similarly, there are genes associated with the biosynthesis and release of coumarins to the rhizosphere, like $F 6^{\prime} H 1, S 8 H$, and $A B C G 37$, that are upregulated both under Fe deficiency and upon colonization of roots by ISR-eliciting microbes. These genes are dependent on FIT $\left(F 6^{\prime} H 1, S 8 H\right)$ or MYB72 (ABCG37) and, consequently, on ET (Figure 2; García et al., 2010; Schmid et al., 2014; Schmidt et al., 2014; Zamioudis et al., 2014; Tsai and Schmidt, 2017a; Siwinska et al., 2018; Tsai et al., 2018; see also Section "Fe deficiency responses in dicot plants").

The results about the relationship of MYB72 and ET are controversial. For example, Van der Ent et al. (2006) showed that MYB72 transcript levels accumulated after treatment with the ET precursor ACC and that they did not accumulate in the Arabidopsis ethylene insensitive mutant ein2-1 upon root colonization with the ISR-eliciting bacterium P. simiae WCS417. However, later on, these authors found that MYB72 transcript levels did not accumulate after treatment with ACC while they accumulated in the ein2-1 mutant upon treatment with $P$. simiae WCS417 (Van der Ent et al., 2008). After these latter results, they concluded that MYB72 expression was not regulated by ET (Van der Ent et al., 2008). Similarly, it was found, by using yeast two-hybrid screening, that MYB72 physically interacted in vitro with EIL3, a TF associated with ET signaling (Van der Ent et al., 2008) while later on it was found, by using Bimolecular Fluorescence Complementation, that MYB72 and EIL3 did not interact in vivo (Zamioudis, 2012). Curiously, EIL3 expression is upregulated both under Fe deficiency (García et al., 2010) and upon colonization of roots with P. simiae WCS417 (Van der Ent et al., 2008). Today, there is enough evidence to support the regulation of FIT, bHLH38, and bHLH39 by ET and, consequently, the one of MYB72. For example, both FIT and MYB72 are upregulated by ET treatment (García et al., 2010). In relation to FIT regulation, it has been shown that the ET-signaling TFs EIN3 and EIL1 interact with FIT to favor its stability and activity (Lingam et al., 2011; Yang et al., 2014; Brumbarova et al., 2015; see Subsection "Ethylene and other hormones and signaling molecules"). The upregulation of MYB72 in the ein2-1 mutant could be explained by taking into account the upregulation of FIT, bHLH38, and bHLH39 in this mutant (García et al., 2010). This could be related to the existence of an alternate route for ethylene signaling, besides the conventional one including EIN2 (Shakeel et al., 2013; Lucena et al., 2015). The complexity of the relationship between MYB72 and ET is also manifested when considering that MYB72 can also affect ET biosynthesis: the SAM1 gene, encoding a SAM synthetase enzyme involved in ET synthesis, is upregulated by MYB72 (Figure 2; Zamioudis et al., 2014) and also is upregulated under Fe deficiency in Arabidopsis roots (García et al., 2010). In accordance with the influence of MYB72 on ET, the exogenous application of ACC induced wildtype levels of resistance in the Arabidopsis myb72-1 mutant, suggesting that MYB72 acts upstream of ET in the ISR pathway (Van der Ent et al., 2008).

Besides the participation of the MYB72, MYB10, FIT, bHLH38, and bHLH39 TFs in both ISR and Fe deficiency responses, there are other TFs that also play a key role in both processes. Among them, the EIN3/EIL1 (related to ET signaling) and MED16 (Mediator) TFs can be highlighted (see Subsection "Ethylene and other hormones and signaling molecules"). These TFs are required to activate the expression of $\mathrm{Fe}$ acquisition genes by interacting with FIT (Figure 2; Lingam et al., 2011; Yang et al., 2014; Zhang et al., 2014; Brumbarova et al., 2015; Lucena et al., 2015). In relation to ISR, the Arabidopsis ein3-1 mutant did not express ISR in response to treatment with the bacterium $P$. simiae WCS417, which suggests that the EIN3 TF also plays a key role in this process (Knoester et al., 1999). MED16 is a key component in the JA/ET-mediated immunity against necrotrophic pathogens (Wang et al., 2015). In addition, and besides affecting the expression of $\mathrm{Fe}$ acquisition genes, it greatly influences the expression of MYB72 and MYB10 (Zhang et al., 2014), two important components in both Fe deficiency responses and ISR (see above). Probably, the physical interaction of MED16 with FIT is necessary for the activation of MYB72 and $M Y B 10$ expression (Figure 2). 
TABLE 2 | Microbial species that improve Fe nutrition when applied to dicot plants grown in calcareous soils (or in artificial calcareous soils).

\begin{tabular}{|c|c|c|c|c|c|}
\hline Microbial species & Plant species & Mode appl. & Fe def. resp. & Fe Gr. & Refs \\
\hline \multicolumn{6}{|l|}{ Rhizobacteria } \\
\hline Bacillus subtilis & Manihot esculenta & ri & nd & $\mathrm{Fe} \wedge$ & Freitas et al., 2015 \\
\hline $\begin{array}{l}\text { Paenibacillus } \\
\text { polymyxa }\end{array}$ & Arabidopsis thaliana & ri & nd & $\mathrm{Fe}$ & Zhou et al., 2016a \\
\hline $\begin{array}{l}\text { Bacillus sp. } \\
\text { Agrobacterium sp.* } \\
\text { Alcaligenes sp.* } \\
\text { Pantoea sp.* }\end{array}$ & Pyrus communis & ri & FCR organic acids & $\mathrm{Fe}$ & Ipek et al., 2017 \\
\hline $\begin{array}{l}\text { Alcaligenes sp.* } \\
\text { Pantoea sp.* }\end{array}$ & Malus domestica & $\mathrm{i}$ & FCR organic acids & $\mathrm{Fe}$ & Aras et al., 2018 \\
\hline $\begin{array}{l}\text { Bacillus sp. } \\
\text { Agrobacterium sp.* } \\
\text { Alcaligenes sp.* } \\
\text { Staphylococcus sp.* }\end{array}$ & Prunus persica & ri & FCR organic acids & $\mathrm{Fe}$ & Arıkan et al., 2018 \\
\hline \multicolumn{6}{|l|}{ Rhizofungi } \\
\hline $\begin{array}{l}\text { Trichoderma } \\
\text { asperellum }\end{array}$ & Lupinus albus & gm and ri & nd & $\mathrm{Fe}$ & de Santiago et al., 2009 \\
\hline $\begin{array}{l}\text { Trichoderma } \\
\text { asperellum }\end{array}$ & Cucumis sativus & ri & nd & $\mathrm{Fe}$ & de Santiago et al., 2013 \\
\hline
\end{tabular}

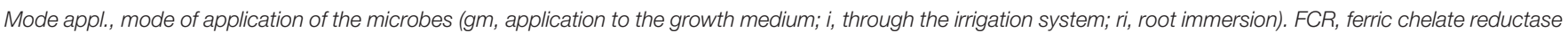

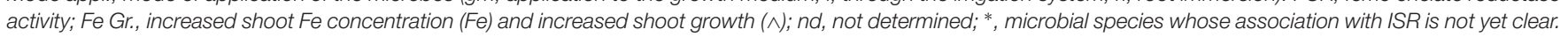

\section{Internal Fe Content}

Eethylene, auxin, and NO greatly activate the expression of $\mathrm{Fe}$ acquisition genes in plants grown with low levels of $\mathrm{Fe}$ (or without $\mathrm{Fe}$ ), but have much less effect in plants grown with high levels of Fe (Lucena et al., 2006; Graziano and Lamattina, 2007; Chen et al., 2010; García et al., 2011). This suggests that the upregulation of $\mathrm{Fe}$ acquisition genes does not solely depend on hormones and signaling molecules (such as ET, auxin, or NO), that would act as activators, but also on the internal Fe content of plants, that would act as a repressor (Lucena et al., 2006; García et al., 2011, 2013, 2018; Romera et al., 2011, 2017). However, different results suggest that total $\mathrm{Fe}$ in roots is not the repressor of Fe acquisition genes but instead it is a Fe-related signal moving from shoots to roots through the phloem (García et al., 2013, 2018). Very recently, it has been found that this shoot Fe-related signal can affect the synthesis of ET on roots (García et al., 2018). To integrate all these regulatory components, a model has been proposed where ET/auxin/NO act as activators of Fe acquisition genes while a phloem Fe-related signal acts as repressor (García et al., 2011, 2013, 2018; Lucena et al., 2015; Romera et al., 2017).

In relation to ISR, there are also several results showing that the effects of ISR-eliciting microbes on the induction of Fe deficiency responses could also be dependent on the $\mathrm{Fe}$ concentration of the medium. For example, the expression of two Fe-related genes, like MYB72, and FRO2, was induced by $P$. simiae WCS417 independently of the Fe concentration in the medium but their absolute values were decreased when the Fe concentration increased (Zamioudis et al., 2015). Other examples, the expression of FIT, IRT1 and FRO2, and the ferric reductase activity, decreased in Arabidopsis plants inoculated with P. polymyxa BFKC01 when the Fe concentration in the medium increased (Zhou et al., 2016a). The expression of FIT, IRT1, FRO1, and HAI, and the ferric reductase activity, in cucumber plants inoculated with Azospirillum brasilense
Cd(DSM-1843) or other rhizobacterial species, decreased when the Fe concentration in the medium increased (Pii et al., 2016b; Scagliola et al., 2016). The acidification capacity induced by the rhizobacterium Arthrobacter agilis in Medicago truncatula roots was lower in plants grown with high levels of $\mathrm{Fe}$ than in those grown with low levels of Fe (Orozco-Mosqueda et al., 2013). Moreover, the expression of several Fe-related genes induced by P. simiae WCS417, like MYB72, FRO2, and IRT1, is transitory (Zamioudis et al., 2015). This suggests that, after the induction of the $\mathrm{Fe}$ acquisition genes by ISR-eliciting microbes, plants acquire enough $\mathrm{Fe}$ and turn off these genes, to avoid toxicity and to conserve energy. The same occurs when plants induce the Fe acquisition genes under Fe deficiency and, as a consequence, they get sufficient Fe (Vert et al., 2003; Lucena et al., 2015).

\section{RHIZOSPHERE MICROBIAL SPECIES THAT INDUCE Fe DEFICIENCY RESPONSES AND IMPROVE Fe ACQUISITION}

As previously stated, beneficial rhizosphere microbes can contribute to improve $\mathrm{Fe}$ acquisition. This is most likely due to their capacity to induce $\mathrm{Fe}$ deficiency responses, such as enhanced ferric reductase activity, acidification of the rhizosphere, release of phenolics and flavins, and development of root hairs (see Section "Interrelationship between ISR and Fe deficiency responses in dicot plants"). These Fe deficiency responses are induced in a similar way as they are induced under $\mathrm{Fe}$ deficiency conditions. For example, ISR-eliciting microbes induce the upregulation of the genes associated with the $\mathrm{Fe}$ deficiency responses, like FRO2, IRT1, AHA, F6'H1, BGLU42, $A B C G 37$, and others, and these genes are activated by the 
TFs that activate them under Fe deficiency, like FIT(FER), bHLH38, bHLH39, MYB72, and MYB10 (Figure 2; Zhang et al., 2009; Palmer et al., 2013; Zamioudis et al., 2014, 2015; Zhao et al., 2014; Pii et al., 2016b; Scagliola et al., 2016; Verbon and Liberman, 2016; Zhou et al., 2016a, 2017, 2018; MartínezMedina et al., 2017; Verbon et al., 2017; Wang J. et al., 2017; Stringlis et al., 2018a,b). Moreover, the hormones and signaling molecules related to the activation of these TFs, like ET, auxin, and NO, are similar in both ISR and Fe deficiency responses (see Subsection "Ethylene and other hormones and signaling molecules").

Among the beneficial rhizosphere microbes that can activate the ISR are rhizobacteria, like $P$. simiae (syn. P. fluorescens), $B$. subtilis, $P$. polymyxa and $A$. brasilense; rhizofungi, like Trichoderma spp.; mycorrhizal fungi, like Rhizophagus irregularis (syn. Glomus intraradices) and $P$. indica; and non-pathogenic races of Fusarium oxysporum (Segarra et al., 2009; Zhang et al., 2009; Patil et al., 2011; Pieterse et al., 2012, 2014; Alizadeh et al., 2013; Zamioudis et al., 2014, 2015; Zhao et al., 2014; Pii et al., 2016b; Martínez-Medina et al., 2017; Verbon et al., 2017). In the case of mycorrhizal fungi, the enhanced defensive capacity provoked by them is also named MIR ("MycorrhizaInduced Resistance") and can favor P acquisition (Jung et al., 2012; Cameron et al., 2013). Furthermore, it has been suggested that MIR can involve an ISR component elicited by bacteria in the mycorrhizosphere (Cameron et al., 2013). This is supported by the synergistic effects in defense responses when both arbuscular mycorrhiza and rhizobacteria are simultaneously applied (Pérez de Luque et al., 2017). The synergy between both kind of microbes paves the way to study the consortia of mycorrhiza and rhizobacteria in relation to the acquisition of Fe and $\mathrm{P}$, and perhaps of other nutrients.

In Table $\mathbf{1}$ are summarized several rhizobacteria and rhizofungi species (most of them trigger ISR) that have been shown to induce $\mathrm{Fe}$ deficiency responses and to improve $\mathrm{Fe}$ acquisition and/or growth when applied to dicot plants. In Table 2 are summarized the ones that have been shown to cause similar effects when applied to dicot plants grown in calcareous soils (or in artificial calcareous soils).

\section{CONCLUDING REMARKS AND FUTURE PERSPECTIVES}

The ability of ISR-eliciting microbes to trigger both defense responses and Fe deficiency responses opens the way to use them as biopesticides and also as Fe biofertilizers. This represents a very important opportunity to diminish the application of fertilizers and pesticides in a more sustainable agriculture. However, and in relation to $\mathrm{Fe}$ nutrition, the use of ISR-eliciting microbes is in its infancy since it is not sufficiently known the behavior of these microbes on crops grown in calcareous soils. Most research works about the realtionship of these microbes with the Fe nutrition of plants have been carried out with Arabidopsis plants grown on agar plates. For their application to crop plants in the field it would be also necessary to study the behavior of these microbes with plant species growing in calcareous soils, including their capacity to thrive in these soils and to compite with wild soil microbes. More research is also needed to know the best ways for their application, by analyzing and comparing, both biologically and economically, the different possibilities, like direct application to soil, root immersion of plantlets before transplanting them (in the case of crop trees), application to seeds, and application into the irrigation systems (probably as spores). In the same way, it is necessary to study whether it is better to apply individual microbial species or consortia of different microbial species (Alizadeh et al., 2013; Sonbarse et al., 2017). In this latter case, and since ET can play a dual role in both ISR and Fe deficiency responses, it would be interesting to analyze the interactions between plant species and microbial species possesing the ACC deaminase enzyme and those that do not. Anyway, the research about ISReliciting microbes and Fe nutrition is a very fascinating topic for the near future.

\section{AUTHOR'S NOTE}

We apologize to authors whose works were not cited in this review due to our ignorance and to manuscript length restrictions. We encourage authors with papers relating ISR and Fe nutrition in dicot plants to send them to us: we are preparing a website (http://www.uco.es/rhizosferrum) to keep updated all the microbial species that elicit ISR, induce Fe deficiency responses, and improve Fe acquisition.

\section{AUTHOR CONTRIBUTIONS}

FR, MG, and CL revised the information related to ISR and Fe deficiency signaling. RP-V revised the information related to volatile compounds. EA, JR, MAA, and MA revised the information related to the different microbial species and their effects on Fe nutrition. FR wrote a first draft of the manuscript. JR, RP-V, and AM-M corrected and improved the manuscript.

\section{FUNDING}

This work was supported by "Plan Propio" Universidad de Córdoba (Spain), the "Junta de Andalucía” (Research Groups AGR115, BIO159, and BIO202) and "LABORATORIOS JAER S.A." (company related to the production of micronutrient fertilizers which is starting to work on micronutrient biofertilizers). The funder played no role in the study design, the collection, analysis or interpretation of data, the writing of this paper or the decision to submit it for publication.

\section{ACKNOWLEDGMENTS}

We thank Dr. Brian M. Waters of the University of Nebraska (Lincoln, United States), for the English correction and valuable suggestions in the editing of the manuscript, and Gabriel Martí ("LABORATORIOS JAER S.A.") for funding the publication of this Review. 


\section{REFERENCES}

Acharya, K., Chandra, S., Chakraborty, N., and Acharya, R. (2011). Nitric oxide functions as a signal in induced systemic resistance. Arch. Phytopathol. Plant Protect. 44, 1335-1342. doi: 10.1080/03235408.2010.496552

Alizadeh, H., Behboudi, K., Ahmadzadeh, M., Javan-Nikkhah, M., Zamioudis, C., Pieterse, C. M. J., et al. (2013). Induced systemic resistance in cucumber and Arabidopsis thaliana by the combination of Trichoderma harzianum $\operatorname{Tr} 6$ and Pseudomonas sp. Ps14. Biol. Control 65, 14-23. doi: 10.1016/j.biocontrol.2013. 01.009

Aparicio, F., and Pallás, V. (2017). The coat protein of Alfalfa mosaic virus interacts and interferes with the transcriptional activity of the bHLH transcription factor ILR3 promoting salicylic acid-dependent defence signaling response. Mol. Plant Pathol. 18, 173-186. doi: 10.1111/mpp.12388

Aras, S., Arıkan, S., İpek, M., Esitken, A., Prrlak, L., Dönmez, M. F., et al. (2018). Plant growth promoting rhizobacteria enhanced leaf organic acids, FC$\mathrm{R}$ activity and $\mathrm{Fe}$ nutrition of apple under lime soil conditions. Acta Physiol. Plant. 40:120. doi: 10.1007/s11738-018-2693-9

Arıkan, S., Esitken, A., İpek, M., Aras, S., Sahin, M., Prrlak, L., et al. (2018). Effect of plant growth promoting rhizobacteria on $\mathrm{Fe}$ acquisition in peach (Prunus persica L.) under calcareous soil conditions. J. Plant Nutr. 41, 2141-2150. doi: 10.1080/01904167.2018.1482910

Asari, S., Tarkowská, D., Rolč́k, J., Novák, O., Velázquez-Palmero, D., Bejai, S., et al. (2017). Analysis of plant growth-promoting properties of Bacillus amyloliquefaciens UCMB5113 using Arabidopsis thaliana as host plant. Planta 245, 15-30. doi: 10.1007/s00425-016-2580-9

Aznar, A., Chen, N. W., Rigault, M., Riache, N., Joseph, D., Desmaële, D., et al. (2014). Scavenging iron: a novel mechanism of plant immunity activation by microbial siderophores. Plant Physiol. 164, 2167-2183. doi: 10.1104/pp.113. 233585

Aznar, A., Chen, N. W. G., Thomine, S., and Dellagi, A. (2015). Immunity to plant pathogens and iron homeostasis. Plant Sci. 240, 90-97. doi: 10.1016/j.plantsci. 2015.08.022

Aznar, A., and Dellagi, A. (2015). New insights into the role of siderophores as triggers of plant immunity: what can we learn from animals? J. Exp. Bot. 66, 3001-3010. doi: 10.1093/jxb/erv155

Bacaicoa, E., Mora, V., Zamarreño, A. M., Fuentes, M., Casanova, E., and GarcíaMina, J. M. (2011). Auxin: a major player in the shoot-to-root regulation of root Fe-stress physiological responses to Fe deficiency in cucumber plants. Plant Physiol. Biochem. 49, 545-556. doi: 10.1016/j.plaphy.2011.02.018

Bacaicoa, E., Zamarreño, A. M., Leménager, D., Baigorri, R., and García-Mina, J. M. (2009). Relationship between the hormonal balance and the regulation of iron deficiency stress responses in cucumber. J. Am. Soc. Hortic. Sci. 134, 589-601. doi: 10.21273/JASHS.134.6.589

Bakker, P. A. H. M., Doornbos, R. F., Zamioudis, C., Berendsen, R. L., and Pieterse, C. M. J. (2013). Induced systemic resistance and the rhizosphere microbiome. Plant Pathol. J. 29, 136-143. doi: 10.5423/PPJ.SI.07.2012.0111

Balmer, D., Planchamp, C., and Mauch-Mani, B. (2013). On the move: induced resistance in monocots. J. Exp. Bot. 64, 1249-1261. doi: 10.1093/jxb/ers248

Bauer, P., Ling, H. Q., and Guerinot, M. L. (2007). FIT, the FER-LIKE IRON DEFICIENCY INDUCED TRANSCRIPTION FACTOR in Arabidopsis. Plant Physiol. Biochem. 45, 260-261. doi: 10.1016/j.plaphy.2007.03.006

Berendsen, R. L., Pieterse, C. M., and Bakker, P. A. (2012). The rhizosphere microbiome and plant health. Trends Plant Sci. 17, 478-486. doi: 10.1016/j. tplants.2012.04.001

Boutrot, F., Segonzac, C., Chang, K. N., Qiao, H., Ecker, J. R., Zipfel, C., et al. (2010). Direct transcriptional control of the Arabidopsis immune receptor FLS2 by the ethylene-dependent transcription factors EIN3 and EIL1. Proc. Natl. Acad. Sci. U.S.A. 107, 14502-14507. doi: 10.1073/pnas. 1003347107

Briat, J. F., Dubos, C., and Gaymard, F. (2015). Iron nutrition, biomass production, and plant product quality. Trends Plant Sci. 20, 33-40. doi: 10.1016/j.tplants. 2014.07.005

Brumbarova, T., Bauer, P., and Ivanov, R. (2015). Molecular mechanisms governing Arabidopsis iron uptake. Trends Plant Sci. 20, 124-133. doi: 10.1016/j.tplants. 2014.11.004

Camehl, I., Sherameti, I., Venus, Y., Bethke, G., Varma, A., Lee, J., et al. (2010). Ethylene signalling and ethylene-targeted transcription factors are required to balance beneficial and nonbeneficial traits in the symbiosis between the endophytic fungus Piriformospora indica and Arabidopsis thaliana. New Phytol. 185, 1062-1073. doi: 10.1111/j.1469-8137.2009.03149.x

Cameron, D. D., Neal, A. L., van Wees, S. C. M., and Ton, J. (2013). Mycorrhizainduced resistance: more than the sum of its parts? Trends Plant Sci. 18, 539-545. doi: 10.1016/j.tplants.2013.06.004

Chen, C. C., Chien, W. F., Lin, N. C., and Yeh, K. C. (2014). Alternative functions of Arabidopsis YELLOW STRIPE-LIKE3: from metal translocation to pathogen defense. PLoS One 9:e98008. doi: 10.1371/journal.pone.0098008

Chen, W. W., Yang, J. L., Qin, C., Jin, C. W., Mo, J. H., Ye, T., et al. (2010). Nitric oxide acts downstream of auxin to trigger root ferric-chelate reductase activity in response to iron deficiency in Arabidopsis thaliana. Plant Physiol. 154, 810-819. doi: 10.1104/pp.110.161109

Choudhary, D. K., Prakash, A., and Johri, B. N. (2007). Induced systemic resistance (ISR) in plants: mechanism of action. Indian J. Microbiol. 47, 289-297. doi: 10.1007/s12088-007-0054-2

Colangelo, E. P., and Guerinot, M. L. (2004). The essential basic helix-loophelix protein FIT1 is required for the iron deficiency response. Plant Cell 16, 3400-3412. doi: 10.1105/tpc. 104.024315

Contreras-Cornejo, H. A., López-Bucio, J. S., Méndez-Bravo, A., MacíasRodríiguez, L. I., Ramos-Vega, M., Guevara-García, Á. A., et al. (2015). Mitogen-activated protein kinase 6 and ethylene and auxin signaling pathways are involved in Arabidopsis root-system architecture alterations by Trichoderma atroviride. Mol. Plant Microbe Interact. 28, 701-710. doi: 10.1094/MPMI-0115-0005-R

de Santiago, A., García-López, A. M., Quintero, J. M., Avilés, M., and Delgado, A. (2013). Effect of Trichoderma asperellum strain T34 and glucose addition on iron nutrition in cucumber grown on calcareous soils. Soil Biol. Biochem. 57, 598-605. doi: 10.1016/j.soilbio.2012.06.020

de Santiago, A., Quintero, J. M., Avilés, M., and Delgado, A. (2009). Effect of Trichoderma asperellum strain T34 on iron nutrition in white lupin. Soil Biol. Biochem. 41, 2453-2459. doi: 10.1016/j.soilbio.2009.07.033

de Zelicourt, A., Al-Yousif, M., and Hirt, H. (2013). Rhizosphere microbes as essential partners for plant stress tolerance. Mol. Plant 6, 242-245. doi: 10.1093/ $\mathrm{mp} / \mathrm{sst} 028$

Dubois, M., Van den Broeck, L., and Inzé, D. (2018). The pivotal role of ethylene in plant growth. Trends Plant Sci. 23, 311-323. doi: 10.1016/j.tplants.2018.01.003

Durrett, T. P., Gassmann, W., and Rogers, E. E. (2007). The FRD3-mediated efflux of citrate into the root vasculature is necessary for efficient iron translocation. Plant Physiol. 144, 197-205. doi: 10.1104/pp.107.097162

Fourcroy, P., Sisó-Terraza, P., Sudre, D., Saviróon, M., Reyt, G., Gaymard, F., et al. (2014). Involvement of the ABCG37 transporter in secretion of scopoletin and derivatives by Arabidopsis roots in response to iron deficiency. New Phytol. 201, 155-167. doi: 10.1111/nph.12471

Fourcroy, P., Tissot, N., Reyt, G., Gaymard, F., Briat, J. F., and Dubos, C. (2016). Facilitated Fe nutrition by phenolic compounds excreted by the Arabidopsis ABCG37/PDR9 transporter requires the IRT1/FRO2 high-affinity root Fe2+ transport system. Mol. Plant 9, 485-488. doi: 10.1016/j.molp.2015. 09.010

Freitas, M. A., Medeiros, F. H. V., Carvalho, S. P., Guilherme, L. R. G., Teixeira, W. D., Zhang, H., et al. (2015). Augmenting iron accumulation in cassava by the beneficial soil bacterium Bacillus subtilis (GBO3). Front. Plant Sci. 6:596. doi: $10.3389 /$ fpls.2015.00596

Gamalero, E., and Glick, B. R. (2015). Bacterial modulation of plant ethylene levels. Plant Physiol. 169, 13-22. doi: 10.1104/pp.15.00284

García, M. J., Corpas, F. J., Lucena, C., Alcántara, E., Pérez-Vicente, R., Zamarreño, Á. M., et al. (2018). A shoot Fe signaling pathway requiring the OPT3 transporter controls GSNO Reductase and ethylene in Arabidopsis thaliana roots. Front. Plant Sci. 9:1325. doi: 10.3389/fpls.2018.01325

García, M. J., Lucena, C., Romera, F. J., Alcántara, E., and Pérez-Vicente, R. (2010). Ethylene and nitric oxide involvement in the up-regulation of key genes related to iron acquisition and homeostasis in Arabidopsis. J. Exp. Bot. 61, 3885-3899. doi: $10.1093 /$ jxb/erl189

García, M. J., Romera, F. J., Stacey, M. G., Stacey, G., Villar, E., Alcántara, E., et al. (2013). Shoot to root communication is necessary to control the expression of iron-acquisition genes in Strategy I plants. Planta 237, 65-75. doi: 10.1007/ s00425-012-1757-0

García, M. J., Suárez, V., Romera, F. J., Alcántara, E., and Pérez-Vicente, R. (2011). A new model involving ethylene, nitric oxide and Fe to explain the regulation 
of Fe-acquisition genes in Strategy I plants. Plant Physiol. Biochem. 49, 537-544. doi: 10.1016/j.plaphy.2011.01.019

García-López, A. M., Avilés, M., and Delgado, A. (2016). Effect of various microorganisms on phosphorus uptake from insoluble Ca-phosphates by cucumber plants. J. Plant Nutr. Soil Sci. 179, 454-465. doi: 10.1002/jpln. 201500024

Garnica-Vergara, A., Barrera-Ortiz, S., Muñoz-Parra, E., Raya-González, J., Méndez-Bravo, A., Macías-Rodríguez, L., et al. (2016). The volatile 6-pentyl2H-pyran-2-one from Trichoderma atroviride regulates Arabidopsis thaliana root morphogenesis via auxin signaling and ETHYLENE INSENSITIVE 2 functioning. New Phytol. 209, 1496-1512. doi: 10.1111/nph.13725

Grady, E. N., MacDonald, J., Liu, L., Richman, A., and Yuan, Z. C. (2016). Current knowledge and perspectives of Paenibacillus: a review. Microb. Cell Fact. 15:203. doi: 10.1186/s12934-016-0603-7

Graziano, M., and Lamattina, L. (2007). Nitric oxide accumulation is required for molecular and physiological responses to iron deficiency in tomato roots. Plant J. 52, 949-960. doi: 10.1111/j.1365-313X.2007.03283.x

Guinel, F. C. (2015). Ethylene, a hormone at the center-stage of nodulation. Front. Plant Sci. 6:1121. doi: 10.3389/fpls.2015.01121

Gullner, G., Komives, T., Király, L., and Schröder, P. (2018). Glutathione S-transferase enzymes in plant-pathogen interactions. Front. Plant Sci. 9:1836. doi: $10.3389 /$ fpls.2018.01836

Gullner, G., Zechmann, B., Künstler, A., and Király, L. (2017). "The signaling roles of glutathione in plant disease resistance," in Glutathione in Plant Growth, Development, and Stress Tolerance, eds M. A. Hossain, M. G. Mostofa, P. D. Vivancos, D. J. Burritt, M. Fujita, and L. S. P. Tran (Cham: Springer International Publishing), 331-357. doi: 10.1007/978-3-319-66682-2_15

Hindt, M. N., Akmakjian, G. Z., Pivarski, K. L., Punshon, T., Baxter, I., Salt, D. E., et al. (2017). BRUTUS and its paralogs, BTS LIKE1 and BTS LIKE2, encode important negative regulators of the iron deficiency response in Arabidopsis thaliana. Metallomics 9, 876-890. doi: 10.1039/c7mt00152e

Hossain, M. M., Sultana, F., and Hyakumachi, M. (2017). Role of ethylene signalling in growth and systemic resistance induction by the plant growthpromoting fungus Penicillium viridicatum in Arabidopsis. J. Phytopathol. 165, 432-441. doi: 10.1111/jph.12577

Ipek, M., Aras, S., Arıkan, S., Esitken, A., Pırlak, L., Dönmez, M. F., et al. (2017). Root plant growth promoting rhizobacteria inoculations increase ferric chelate reductase (FC-R) activity and Fe nutrition in pear under calcareous soil conditions. Sci. Hortic. 219, 144-151. doi: 10.1016/j.scienta.2017.02.043

İpek, M., and Eşitken, A. (2017). "The actions of PGPR on micronutrient availability in soil and plant under calcareous soil conditions: an evaluation over Fe nutrition," in Plant-Microbe Interactions in Agro-Ecological Perspectives, Vol. 2, eds D. Singh, H. Singh, and R. Prabha (Singapore: Springer), 81-100.

Ivanov, R., Brumbarova, T., and Bauer, P. (2012). Fitting into the harsh reality: regulation of iron-deficiency responses in dicotyledonous plants. Mol. Plant 5, 27-42. doi: 10.1093/mp/ssr065

Jankiewicz, U., and Koltonowicz, M. (2012). The involvement of Pseudomonas bacteria in induced systemic resistance in plants (Review). Appl. Biochem. Microbiol. 48, 244-249. doi: 10.1134/S0003683812030052

Jin, C. W., Ye, Y. Q., and Zheng, S. J. (2014). An underground tale: contribution of microbial activity to plant iron acquisition via ecological processes. Ann. Bot. 113, 7-18. doi: 10.1093/aob/mct249

Jung, S. C., Martinez-Medina, A., Lopez-Raez, J. A., and Pozo, M. J. (2012). Mycorrhiza-Induced Resistance and priming of plant defenses. J. Chem. Ecol. 38, 651-664. doi: 10.1007/s10886-012-0134-6

Kabir, A. H., Paltridge, N. G., Able, A. J., Paull, J. G., and Stangoulis, J. C. R. (2012). Natural variation for Fe-efficiency is associated with up-regulation of Strategy I mechanisms and enhanced citrate and ethylene synthesis in Pisum sativum L. Planta 235, 1409-1419. doi: 10.1007/s00425-011-1583-9

Kailasam, S., Wang, Y., Lo, J. C., Chang, H. F., and Yeh, K. C. (2018). S-nitrosoglutathione works downstream of nitric oxide to mediate iron deficiency signaling in Arabidopsis. Plant J. 94, 157-168. doi: 10.1111/tpj.13850

Kang, H. G., Foley, R. C., Onate-Sanchez, L., Lin, C., and Singh, K. B. (2003). Target genes for OBP3, a Dof transcription factor, include novel basic helixloop-helix domain proteins inducible by salicylic acid. Plant J. 35, 362-372. doi: 10.1046/j.1365-313X.2003.01812.x

Kieu, N. P., Aznar, A., Segond, D., Rigault, M., Simond-Côte, E., Kunz, C., et al. (2012). Iron deficiency affects plant defence responses and confers resistance to Dickeya dadantii and Botrytis cinerea. Mol. Plant Pathol. 13, 816-827. doi: 10.1111/J.1364-3703.2012.00790.X

Knoester, M., Pieterse, C. M. J., Bol, J. F., and Van Loon, L. C. (1999). Systemic resistance in Arabidopsis induced by rhizobacteria requires ethylene-dependent signaling at the site of application. Mol. Plant Microbe Interact. 12, 720-727. doi: 10.1094/MPMI.1999.12.8.720

Kobayashi, T., Itai, R. N., Senoura, T., Oikawa, T., Ishimaru, Y., Ueda, M., et al. (2016). Jasmonate signaling is activated in the very early stages of iron deficiency responses in rice roots. Plant Mol. Biol. 91, 533-547. doi: 10.1007/s11103-0160486-3

Kobayashi, T., and Nishizawa, N. K. (2012). Iron uptake, translocation, and regulation in higher plants. Annu. Rev. Plant Biol. 63, 131-152. doi: 10.1146/ annurev-arplant-042811-10552

Koen, E., Szymańska, K., Klinguer, A., Dobrowolska, G., Besson-Bard, A., and Wendehenne, D. (2012). Nitric oxide and glutathione impact the expression of iron uptake- and iron transport-related genes as well as the content of metals in A. thaliana plants grown under iron deficiency. Plant Signal. Behav. 7, 1246-1250. doi: 10.4161/psb.21548

Kudoyarova, G. R., Vysotskaya, L. B., Arkhipova, T. N., Kuzmina, L. Y., Galimsyanova, N. F., Sidorova, L. V., et al. (2017). Effect of auxin producing and phosphate solubilizing bacteria on mobility of soil phosphorus, growth rate, and P acquisition by wheat plants. Acta Physiol. Plant. 39:253. doi: 10.1007/s11738017-2556-9

Kumar, R. K., Chu, H. H., Abundis, C., Vasques, K., Rodriguez, D. C., Chia, J. C., et al. (2017). Iron-nicotianamine transporters are required for proper long distance iron signaling. Plant Physiol. 175, 1254-1268. doi: 10.1104/pp.17.00821

Kwon, Y. S., Ryu, C.-M., Lee, S., Park, H. B., Han, K. S., Lee, J. H., et al. (2010). Proteome analysis of Arabidopsis seedlings exposed to bacterial volatiles. Planta 232, 1355-1370. doi: 10.1007/s00425-010-1259-x

Lemanceau, P., Expert, D., Gaymard, F., Bakker, P. A. H. M., and Briat, J. F. (2009). Role of iron in plant-microbe interactions. Adv. Bot. Res. 51, 491-549. doi: 10.1016/S0065-2296(09)51012-9

Li, G., Meng, X., Wang, R., Mao, G., Han, L., Liu, Y., et al. (2012). Duallevel regulation of ACC synthase activity by MPK3/MPK6 cascade and its downstream WRKY transcription factor during ethylene induction in Arabidopsis. PLoS Genet. 8:e1002767. doi: 10.1371/journal.pgen.1002767

Li, R.-X., Cai, F., Pang, G., Shen, Q.-R., Li, R., and Chen, W. (2015). Solubilisation of phosphate and micronutrients by Trichoderma harzianum and its relationship with the promotion of tomato plant growth. PLoS One 10:e0130081. doi: 10. 1371/journal.pone.0130081

Li, W., and Lan, P. (2017). The understanding of the plant iron deficiency responses in Strategy I plants and the role of ethylene in this process by omic approaches. Front. Plant Sci. 8:40. doi: 10.3389/fpls.2017.00040

Li, X., Zhang, H., Ai, Q., Liang, G., and Yu, D. (2016). Two bHLH transcription factors, bHLH34 and bHLH104, regulate iron homeostasis in Arabidopsis thaliana. Plant Physiol. 170, 2478-2493. doi: 10.1104/pp.15.01827

Liang, G., Zhang, H., Li, X., Ai, Q., and Yu, D. (2017). bHLH transcription factor bHLH115 regulates iron homeostasis in Arabidopsis thaliana. J. Exp. Bot. 68, 1743-1755. doi: 10.1093/jxb/erx043

Lin, X. Y., Ye, Y. Q., Fan, S. K., Jin, C. W., and Zheng, S. J. (2016). Increased sucrose accumulation regulates iron-deficiency responses by promoting auxin signaling in Arabidopsis plants. Plant Physiol. 170, 907-920. doi: 10.1104/pp.15.01598

Lingam, S., Mohrbacher, J., Brumbarova, T., Potuschak, T., Fink-Straube, C., Blondet, E., et al. (2011). Interaction between the bHLH transcription factor FIT and the ETHILENE INSENSITIVE3/ ETHYLENE INSENSITIVE3-LIKE1 reveals molecular linkage between the regulation of iron acquisition and ethylene signaling in Arabidopsis. Plant Cell 23, 1815-1829. doi: 10.1105/tpc. 111.084715

Liu, W., Karemera, N. J. U., Wu, T., Yang, Y., Zhang, X., Xu, X., et al. (2017a). The ethylene response factor AtERF4 negatively regulates the iron deficiency response in Arabidopsis thaliana. PLoS One 12:e0186580. doi: 10.1371/journal. pone. 0186580

Liu, W., Li, Q., Wang, Y., Wu, T., Yang, Y., Zhang, X., et al. (2017b). Ethylene response factor AtERF72 negatively regulates Arabidopsis thaliana response to iron deficiency. Biochem. Biophys. Res. Commun. 491, 862-868. doi: 10.1016/j. bbrc.2017.04.014

Liu, X. M., and Zhang, H. (2015). The effects of bacterial volatile emissions on plant abiotic stress tolerance. Front. Plant Sci. 6:774. doi: 10.3389/fpls.2015.00774 
López-Berges, M., Turra, D., Capilla, J., Schafferer, L., Matthijs, S., Jöchl, C., et al. (2013). Iron competition in fungus-plant interactions: the battle takes place in the rhizosphere. Plant Signal. Behav. 8:e23012. doi: 10.4161/psb.23012

Lucena, C., Romera, F. J., García, M. J., Alcántara, E., and Pérez-Vicente, R. (2015). Ethylene participates in the regulation of Fe deficiency responses in Strategy I plants and in rice. Front. Plant Sci. 6:1056. doi: 10.3389/fpls.2015.01056

Lucena, C., Romera, F. J., Rojas, C. L., García, M. J., Alcántara, E., and PérezVicente, R. (2007). Bicarbonate blocks the expression of several genes involved in the physiological responses to Fe deficiency of Strategy I plants. Funct. Plant Biol. 34, 1002-1009. doi: 10.1071/FP07136

Lucena, C., Waters, B. M., Romera, F. J., García, M. J., Morales, M., Alcántara, E., et al. (2006). Ethylene could influence ferric reductase, iron transporter and $\mathrm{H}+$-ATPase gene expression by affecting FER (or FER-like) gene activity. J. Exp. Bot. 57, 4145-4154. doi: 10.1093/jxb/erl189

Martinez-Medina, A., Flors, V., Heil, M., Mauch-Mani, B., Pieterse, C. M. J., Pozo, M. J., et al. (2016). Recognizing plant defense priming. Trends Plant Sci. 21, 818-822. doi: 10.1016/j.tplants.2016.07.009

Martínez-Medina, A., Van Wees, S. C. M., and Pieterse, C. M. J. (2017). Airborne signals from Trichoderma fungi stimulate iron uptake responses in roots resulting in priming of jasmonic acid dependent defences in shoots of Arabidopsis thaliana and Solanum lycopersicum. Plant Cell Environ. 40, 2691-2705. doi: 10.1111/pce.13016

Maurer, F., Müller, S., and Bauer, P. (2011). Suppression of Fe deficiency gene expression by jasmonate. Plant Physiol. Biochem. 49, 530-536. doi: 10.1016/j. plaphy.2011.01.025

Maurer, F., Naranjo Arcos, M. A., and Bauer, P. (2014). Responses of a triple mutant defective in three iron deficiency-induced Basic Helix-Loop-Helix genes of the subgroup $\mathrm{Ib}(2)$ to iron deficiency and salicylic acid. PLoS One 9:e99234. doi: 10.1371/journal.pone.0099234

Meiser, J., Lingam, S., and Bauer, P. (2011). Post-transcriptional regulation of the Fe deficiency bHLH transcription factor FIT is affected by iron and nitric oxide. Plant Physiol. 157, 2154-2166. doi: 10.1104/pp.111.183285

Meziane, H., Van der Sluis, I., Van Loon, L. C., Höfte, M., and Bakker, P. A. (2005). Determinants of Pseudomonas putida WCS358 involved in inducing systemic resistance in plants. Mol. Plant Pathol. 6, 177-185. doi: 10.1111/j.1364-3703. 2005.00276.x

Mimmo, T., Del Buono, D., Terzano, R., Tomasi, N., Vigani, G., Crecchio, C., et al. (2014). Rhizospheric organic compounds in the soil-microorganism-plant system: their role in iron availability. Eur. J. Soil Sci. 65, 629-642. doi: 10.1111/ ejss. 12158

Naranjo-Arcos, M. A., and Bauer, P. (2016). "Iron nutrition, oxidative stress, and pathogen defense," in Nutritional Deficiency, eds P. Erkekoglu and B. Kocer-Gumusel (Rijeka: InTechOpen), 63-98. doi: 10.5772/63204

Nascimento, F. X., Rossi, M. J., and Glick, B. R. (2018). Ethylene and 1-aminocyclopropane-1-carboxylate (ACC) in plant-bacterial interactions. Front. Plant Sci. 9:114. doi: 10.3389/fpls.2018.00114

Nie, P., Li, X., Wang, S., Guo, J., Zhao, H., and Niu, D. (2017). Induced systemic resistance against Botrytis cinerea by Bacillus cereus AR156 through a JA/ET- and NPR1-dependent signaling pathway and activates PAMP-triggered immunity in Arabidopsis. Front. Plant Sci. 8:238. doi: 10.3389/fpls.2017.00238

Orozco-Mosqueda, M. C., Velázquez-Becerra, C., Macías-Rodríguez, L. I., Santoyo, G., Flores-Cortez, I., Alfaro-Cuevas, R., et al. (2013). Arthrobacter agilis UMCV2 induces iron acquisition in Medicago truncatula (Strategy I plant) in vitro via dimethylhexadecylamine emission. Plant Soil 362, 51-66. doi: 10.1007/s11104-012-1263-y

Palmer, C. M., Hind, M. N., Schmidt, H., Clemens, S., and Guerinot, M. L. (2013). MYB10 and MYB72 are required for growth under iron-limiting conditions. PLoS Genet. 9:e1003953. doi: 10.1371/journal.pgen.1003953

Patel, T., and Saraf, M. (2017). Biosynthesis of phytohormones from novel rhizobacterial isolates and their in vitro plant growth-promoting efficacy. J. Plant Interact. 12, 480-487. doi: 10.1080/17429145.2017.1392625

Patil, S., Sriram, S., Savitha, M. J., and Arulmani, N. (2011). Induced systemic resistance in tomato by non-pathogenic Fusarium species for the management of Fusarium wilt. Arch. Phytopathol. Plant Protect. 44, 1621-1634. doi: 10.1080/ 03235408.2010.526774

Pérez de Luque, A., Tille, S., Johnson, I., Pascual-Pardo, D., Ton, J., and Cameron, D. D. (2017). The interactive effects of arbuscular mycorrhiza and plant growth-promoting rhizobacteria synergistically enhance host plant defences against pathogens. Sci. Rep. 7:16409. doi: 10.1038/s41598-01716697-4

Pierik, R., Sasidharan, R., and Voesenek, L. A. C. J. (2007). Growth control by ethylene: adjusting phenotypes to the environment. J. Plant Growth Regul. 26, 188-200. doi: 10.1007/s00344-006-0124-4

Pieterse, C. M. J., Van der Does, D., Zamioudis, C., Leon-Reyes, A., and Van Wees, S. C. M. (2012). Hormonal modulation of plant immunity. Annu. Rev. Cell Dev. Biol. 28, 489-521. doi: 10.1146/annurev-cellbio-092910-154055

Pieterse, C. M. J., Van Wees, S. C. M., Ton, J., Van Pelt, J. A., and Van Loon, L. C. (2002). Signalling in rhizobacteria-lnduced systemic resistance in Arabidopsis thaliana. Plant Biol. 4, 535-544. doi: 10.1055/s-2002-354411

Pieterse, C. M. J., Van Wees, S. C. M., van Pelt, J. A., Knoester, M., Laan, R., Gerrits, H., et al. (1998). A novel signaling pathway controlling induced systemic resistance in Arabidopsis. Plant Cell 10, 1571-1580. doi: 10.1105/tpc. 10.9.1571

Pieterse, C. M. J., Zamioudis, C., Berendsen, R. L., Weller, D. M., Van Wees, S. C. M., and Bakker, P. A. H. M. (2014). Induced systemic resistance by beneficial microbes. Annu. Rev. Phytopathol. 52, 347-375. doi: 10.1146/ annurev-phyto-082712-102340

Pii, Y., Borruso, L., Brusetti, L., Crecchio, C., Cesco, S., and Mimmo, T. (2016a). The interaction between iron nutrition, plant species and soil type shapes the rhizosphere microbiome. Plant Physiol. Biochem. 99, 39-48. doi: 10.1016/j. plaphy.2015.12.002

Pii, Y., Marastoni, L., Springeth, C., Fontanella, M. C., Beone, G. M., Cesco, S., et al. (2016b). Modulation of Fe acquisition process by Azospirillum brasilense in cucumber plants. Environ. Exp. Bot. 130, 216-225. doi: 10.1016/j.envexpbot. 2016.06.011

Pii, Y., Mimmo, T., Tomasi, N., Terzano, R., Cesco, S., and Crecchio, C. (2015). Microbial interactions in the rhizosphere: beneficial influences of plant growthpromoting rhizobacteria on nutrient acquisition process. A review. Biol. Fertil. Soils 51, 403-415. doi: 10.1007/s00374-015-0996-1

Pommerrenig, B., Feussner, K., Zierer, W., Rabinovych, V., Klebl, F., Feussner, I., et al. (2011). Phloem-specific expression of Yang cycle genes and identification of novel Yang cycle enzymes in Plantago and Arabidopsis. Plant Cell 23, 1904-1919. doi: 10.1105/tpc.110.079657

Poupin, M. J., Greve, M., Carmona, V., and Pinedo, I. (2016). A complex molecular interplay of auxin and ethylene signaling pathways is involved in Arabidopsis growth promotion by Burkholderia phytofirmans PsJN. Front. Plant Sci. 7:492. doi: $10.3389 /$ fpls.2016.00492

Rajniak, J., Giehl, R. F. H., Chang, E., Murgia, I., von Wirén, N., and Sattely, E. S. (2018). Biosynthesis of redox-active metabolites in response to iron deficiency in plants. Nat. Chem. Biol. 14, 442-450. doi: 10.1038/s41589-018-0019-2

Ribaudo, C. M., Krumpholz, E. M., Cassán, F. D., Bottini, R., Cantore, M. L., and Curá, J. A. (2006). Azospirillum sp. promotes root hair development in tomato plants through a mechanism that involves ethylene. J. Plant Growth Regul. 24, 175-185. doi: 10.1007/s00344-005-0128-5

Rodríguez-Celma, J., and Schmidt, W. (2013). Reduction-based iron uptake revisited. On the role of secreted iron-binding compounds. Plant Signal. Behav. 8:e26116. doi: 10.4161/psb.26116

Romera, F. J., and Alcántara, E. (1994). Iron-deficiency stress responses in cucumber (Cucumis sativus L.) roots. A possible role for ethylene? Plant Physiol. $105,1133-1138$.

Romera, F. J., and Alcántara, E. (2004). Ethylene involvement in the regulation of Fe-deficiency stress responses by Strategy I plants. Funct. Plant Biol. 31, 315-328. doi: 10.1071/FP03165

Romera, F. J., Alcántara, E., and De la Guardia, M. D. (1999). Ethylene production by $\mathrm{Fe}$-deficient roots and its involvement in the regulation of Fe-deficiency stress responses by Strategy I plants. Ann. Bot. 83, 51-55. doi: 10.1006/anbo. 1998.0793

Romera, F. J., García, M. J., Alcántara, E., and Pérez-Vicente, R. (2011). Latest findings about the interplay or auxin, ethylene and nitric oxide in the regulation of Fe deficiency responses by Strategy I plants. Plant Signal. Behav. 6, 167-170. doi: $10.4161 /$ psb.6.1.14111

Romera, F. J., Lucena, C., García, M. J., Alcántara, E., and Pérez-Vicente, R. (2017). "The role of ethylene and other signals in the regulation of $\mathrm{Fe}$ deficiency responses by dicot plants," in Stress Signaling in Plants: Genomics and Proteomics Perspectives, Vol. 2, eds M. Sarwat, A. Ahmad, M. Z. Abdin, and M. Ibrahim (Cham: Springer), 277-300. 
Römheld, V., and Marschner, H. (1986). Mobilization of iron in the rhizosphere of different plant species. Adv. Plant Nutr. 2, 155-204. doi: 10.1007/BF0222 0801

Ryu, C.-M., Hu, C.-H., Reddy, M. S., and Kloepper, J. W. (2003). Different signaling pathways of induced resistance by rhizobacteria in Arabidopsis thaliana against two pathovars of Pseudomonas syringae. New Phytol. 160, 413-420. doi: 10. 1046/j.1469-8137.2003.00883.x

Sauter, M., Moffatt, B., Saechao, M. C., Hell, R., and Wirtz, M. (2013). Methionine salvage and $S$-adenosylmethionine: essential links between sulfur, ethylene and polyamine biosynthesis. Biochem. J. 451, 145-154. doi: 10.1042/BJ201 21744

Savary, S., Ficke, A., Aubertot, J. N., and Hollier, C. (2012). Crop losses due to diseases and their implications for global food production losses and food security. Food Secur. 4, 519-537. doi: 10.1007/s12571-012-0200-5

Scagliola, M., Pii, Y., Mimmo, T., Cesco, S., Ricciuti, P., and Crecchio, C. (2016). Characterization of plant growth promoting traits of bacterial isolates from the rhizosphere of barley (Hordeum vulgare L.) and tomato (Solanum lycopersicon L.) grown under Fe sufficiency and deficiency. Plant Physiol. Biochem. 107, 187-196. doi: 10.1016/j.plaphy.2016.06.002

Schmid, N. B., Giehl, R. F. H., Döll, S., Mock, H. P., Strehmel, N., Scheel, D., et al. (2014). Feruloyl-CoA 6'-Hydroxylase1-dependent coumarins mediate iron acquisition from alkaline substrates in Arabidopsis. Plant Physiol. 164, 160-172. doi: 10.1104/pp.113.228544

Schmidt, H., Günther, C., Weber, M., Spörlein, C., Loscher, S., Böttcher, C., et al. (2014). Metabolome analysis of Arabidopsis thaliana roots identifies a key metabolic pathway for iron acquisition. PLoS One 9:e102444. doi: 10.1371/ journal.pone.0102444

Segarra, G., Van der Ent, S., Trillas, I., and Pieterse, C. M. J. (2009). MYB72, a node of convergence in induced systemic resistance triggered by a fungal and a bacterial beneficial microbe. Plant Biol. 11, 90-96. doi: 10.1111/j.1438-8677. 2008.00162.x

Séguéla, M., Briat, J. F., Vert, G., and Curie, C. (2008). Cytokinins negatively regulate the root iron uptake machinery in Arabidopsis through a growthdependent pathway. Plant J. 55, 289-300. doi: 10.1111/j.1365-313X.2008. 03502.x

Shakeel, S. N., Wang, X., Binder, B. M., and Schaller, G. E. (2013). Mechanisms of signal transduction by ethylene: overlapping and non-overlapping signalling roles in a receptor family. AoB Plants 5:1t010. doi: 10.1093/aobpla/plt010

Shanmugam, V., Wang, Y. W., Tsednee, M., Karunakaran, K., and Yeh, K. C. (2015). Glutathione plays an essential role in nitric oxide-mediated irondeficiency signaling and iron-deficiency tolerance in Arabidopsis. Plant J. 84, 464-477. doi: 10.1111/tpj.13011

Sharifi, R., and Ryu, C. M. (2018). Sniffing bacterial volatile compounds for healthier plants. Curr. Opin. Plant Biol. 44, 88-97. doi: 10.1016/j.pbi.2018. 03.004

Shen, C., Yang, Y., Liu, K., Zhang, L., Guo, H., Sun, T., et al. (2016). Involvement of endogenous salicylic acid in iron-deficiency responses in Arabidopsis. J. Exp. Bot. 67, 4179-4193. doi: 10.1093/jxb/erw196

Shen, J., Li, C., Mi, G., Li, L., Yuan, L., Jiang, R., et al. (2013). Maximizing root/rhizosphere efficiency to improve crop productivity and nutrient use efficiency in intensive agriculture of China. J. Exp. Bot. 64, 1181-1192. doi: 10.1093/jxb/ers342

Shoresh, M., Yedidia, I., and Chet, I. (2005). Involvement of jasmonic acid/ethylene signaling pathway in the systemic resistance induced in cucumber by Trichoderma asperellum T203. Phytopathology 95, 76-84. doi: 10.1094/ PHYTO-95-0076

Singh, R. P., Shelke, G. M., Kumar, A., and Jha, P. N. (2015). Biochemistry and genetics of ACC deaminase: a weapon to "stress ethylene" produced in plants. Front. Microbiol. 6:937. doi: 10.3389/fmicb.2015.00937

Sivitz, A. B., Hermand, V., Curie, C., and Vert, G. (2012). Arabidopsis bHLH100 and bHLH101 control iron homeostasis via a FIT-independent pathway. PLoS One 7:e44843. doi: 10.1371/journal.pone.0044843

Siwinska, J., Siatkowska, K., Olry, A., Grosjean, J., Hehn, A., Bourgaud, F., et al. (2018). Scopoletin 8-hydroxylase: a novel enzyme involved in coumarin biosynthesis and iron-deficiency responses in Arabidopsis. J. Exp. Bot. 69, 1735-1748. doi: 10.1093/jxb/ery005

Sonbarse, P. P., Sharma, P., and Parvatam, G. (2017). PGPR's mix treatment to Moringa improved plant growth and iron content in foliage as substantiated by biochemical and molecular methods. J. Plant Interact. 12, 526-532. doi: 10.1080/17429145.2017.1400125

Stringlis, I. A., Proietti, S., Hickman, R., Van Verk, M. C., Zamioudis, C., and Pieterse, C. M. J. (2018a). Root transcriptional dynamics induced by beneficial rhizobacteria and microbial immune elicitors reveal signatures of adaptation to mutualists. Plant J. 93, 166-180. doi: 10.1111/tpj.13741

Stringlis, I. A., Yua, K., Feussnerb, K., de Jonge, R., Van Bentum, S., Van Verk, M. C., et al. (2018b). MYB72-dependent coumarin exudation shapes root microbiome assembly to promote plant health. Proc. Natl. Acad. Sci. U.S.A. 115, E5213-E5222. doi: 10.1073/pnas.1722335115

Sumayo, M. M., Son, J.-S., and Ghim, S.-Y. (2018). Exogenous application of phenylacetic acid promotes root hair growth and induces the systemic resistance of tobacco against bacterial soft-rot pathogen Pectobacterium carotovorum subsp. carotovorum. Funct. Plant Biol. 45, 1119-1127. doi: 10. 1071/FP17332

Ton, J., Davison, S., Van Wees, S. C. M., Van Loon, L. C., and Pieterse, C. M. J. (2001). The Arabidopsis ISR1 locus controlling rhizobacteria-mediated induced systemic resistance is involved in ethylene signaling. Plant Physiol. 125, 652661. doi: 10.1104/pp.125.2.652

Tsai, H. H., Rodríguez-Celma, J., Lan, P., Wu, Y. C., Vélez-Bermúdez, I. C., and Schmidt, W. (2018). Scopoletin 8-Hydroxylase-mediated fraxetin production is crucial for iron mobilization. Plant Physiol. 177, 194-207. doi: 10.1104/pp.18. 00178

Tsai, H. H., and Schmidt, W. (2017a). Mobilization of iron by plant-borne coumarins. Trends Plant Sci. 22, 538-548. doi: 10.1016/j.tplants.2017.03.008

Tsai, H. H., and Schmidt, W. (2017b). One way. Or another? Iron uptake in plants. New Phytol. 214, 500-505. doi: 10.1111/nph.14477

Tyagi, S., Mulla, S. I., Lee, K. J., Chae, J. C., and Shukla, P. (2018). VOCs-mediated hormonal signaling and crosstalk with plant growth promoting microbes. Crit. Rev. Biotechnol. 38, 1277-1296. doi: 10.1080/07388551.2018.1472551

Van der Ent, S. (2008). Transcriptional Regulators of Rhizobacteria Induced Systemic Resistance. Ph.D. Thesis, Utrecht University Repository, Utrecht.

Van der Ent, S., Pozo, M. J., Verhagen, B. W. M., Bakker, D., Van Loon, L. C., and Pieterse, C. M. J. (2006). Transcription factors in roots and shoots of Arabidopsis involved in rhizobacteria-induced systemic resistance. IOBC/WPRS Bull. 29, 157-161.

Van der Ent, S., Verhagen, B. W. M., Van Doorn, R., Bakker, D., Verlaan, M. G., Pel, M. J. C., et al. (2008). MYB72 is required in early signaling steps of rhizobacteria induced systemic resistance in Arabidopsis. Plant Physiol. 146, 1293-1304. doi: 10.1104/pp.107.113829

Van Loon, L. C., Bakker, P. A. H. M., and Pieterse, C. M. J. (1998). Systemic resistance induced by rhizosphere bacteria. Annu. Rev. Phytopathol. 36, 453483. doi: 10.1146/annurev.phyto.36.1.453

Van Loon, L. C., Geraats, B. P. J., and Linthorst, H. J. M. (2006). Ethylene as a modulator of disease resistance in plants. Trends Plant Sci. 11, 184-191. doi: 10.1016/j.tplants.2006.02.005

Velivelli, S. L. S., Lojan, P., Cranenbrouck, S., Dupré de Boulois, H., Suarez, J. P., Declerck, S., et al. (2015). The induction of Ethylene Response Factor 3 (ERF3) in potato as a result of co-inoculation with Pseudomonas sp. R41805 and Rhizophagus irregularis MUCL 41833 - a possible role in plant defense. Plant Signal. Behav. 10:e988076. doi: 10.4161/15592324.2014.988076

Verbon, E. H., and Liberman, L. M. (2016). Beneficial microbes affect endogenous mechanisms controlling root development. Trends Plant Sci. 21, 218-229. doi: 10.1016/j.tplants.2016.01.013

Verbon, E. H., Trapet, P. L., Stringlis, I. A., Kruijs, S., Bakker, P. A. H. M., and Pieterse, C. M. J. (2017). Iron and immunity. Annu. Rev. Phytopathol. 55, 355-375. doi: 10.1146/annurev-phyto-080516-035537

Verhagen, B. W. M., Glazebrook, J., Zhu, T., Chang, H.-S., Van Loon, L. C., and Pieterse, C. M. J. (2004). The transcriptome of rhizobacteria-induced systemic resistance in Arabidopsis. Mol. Plant Microbe Interact. 17, 895-908. doi: 10. 1094/MPMI.2004.17.8.895

Vert, G. A., Briat, J. F., and Curie, C. (2003). Dual regulation of the Arabidopsis high-affinity root iron uptake system by local and long-distance signals. Plant Physiol. 132, 796-804. doi: 10.1104/pp.102.016089

Villena, J., Kitazawa, H., Van Wees, S. C. M., Pieterse, C. M. J., and Takahashi, H. (2018). Receptors and signaling pathways for recognition of bacteria in livestock and crops: prospects for beneficial microbes in healthy growth strategies. Front. Immunol. 9:2223. doi: 10.3389/fimmu.2018.02223 
Wang, B., Li, Y., and Zhang, W. H. (2012). Brassinosteroids are involved in response of cucumber (Cucumis sativus) to iron deficiency. Ann. Bot. 110, 681-688. doi: 10.1093/aob/mcs126

Wang, C., Yao, J., Du, X., Zhang, Y., Sun, Y., Rollins, J. A., et al. (2015). The Arabidopsis Mediator Complex Subunit16 is a key component of basal resistance against the necrotrophic fungal pathogen Sclerotinia sclerotiorum. Plant Physiol. 169, 856-872. doi: 10.1104/pp.15.00351

Wang, F., Cui, X., Sun, Y., and Dong, C. H. (2013). Ethylene signaling and regulation in plant growth and stress responses. Plant Cell Rep. 32, 1099-1109. doi: 10.1007/s00299-013-1421-6

Wang, N., Cui, Y., Liu, Y., Fan, H., Du, J., Huang, Z., et al. (2013). Requirement and functional redundancy of Ib subgroup bHLH proteins for iron deficiency responses and uptake in Arabidopsis thaliana. Mol. Plant 6, 503-513. doi: 10. 1093/mp/sss089

Wang, J., Zhou, C., Xiao, X., Xie, Y., Zhu, L., and Ma, Z. (2017). Enhanced iron and selenium uptake in plants by volatile emissions of Bacillus amyloliquefaciens (BF06). Appl. Sci. 7:85. doi: 10.3390/app7010085

Wang, W., Shi, J., Xie, Q., Jiang, Y., Yu, N., and Wang, E. (2017). Nutrient exchange and regulation in arbuscular mycorrhizal symbiosis. Mol. Plant 10, 1147-1158. doi: 10.1016/j.molp.2017.07.012

Waters, B. M., Lucena, C., Romera, F. J., Jester, G. G., Wynn, A. N., Rojas, C. L., et al. (2007). Ethylene involvement in the regulation of the H+-ATPase CsHA1 gene and of the new isolated ferric reductase CsFRO1 and iron transporter CsIRT1 genes in cucumber plants. Plant Physiol. Biochem. 45, 293-301. doi: 10.1016/j.plaphy.2007.03.011

Yang, J., Kloepper, J. W., and Ryu, C. M. (2008). Rhizosphere bacteria help plants tolerate abiotic stress. Trends Plant Sci. 14, 1-4. doi: 10.1016/j.tplants.2008. 10.004

Yang, Y., Ou, B., Zhang, J., Si, W., Gu, H., Qin, G., et al. (2014). The Arabidopsis Mediator subunit MED16 regulates iron homeostasis by associating with EIN3/EIL1 through subunit MED25. Plant J. 77, 838-851. doi: 10.1111/tpj. 12440

Ye, L., Li, L., Wang, L., Wang, S., Li, S., Du, J., et al. (2015). MPK3/MPK6 are involved in iron deficiency-induced ethylene production in Arabidopsis. Front. Plant Sci. 6:953. doi: 10.3389/fpls.2015.00953

Yuan, Y. X., Wu, H. L., Wang, N., Li, J., Zhao, W. N., Du, J., et al. (2008). FIT interacts with AtbHLH038 and AtbHLH039 in regulating iron uptake gene expression for iron homeostasis in Arabidopsis. Cell Res. 18, 385-397. doi: $10.1038 / \mathrm{cr} .2008 .26$

Yun, B. W., Skelly, M. J., Yin, M., Yu, M., Mun, B. G., Lee, S. U., et al. (2016). Nitric oxide and $S$-nitrosoglutathione function additively during plant immunity. New Phytol. 211, 516-526. doi: 10.1111/nph.13903

Zamioudis, C. (2012). Signaling in Arabidopsis Roots in Response to Beneficial Rhizobacteria. Ph.D. Thesis, Utrecht University, Utrecht.

Zamioudis, C., Hanson, J., and Pieterse, C. M. J. (2014). $\beta$-Glucosidase BGLU42 is a MYB72-dependent key regulator of rhizobacteria-induced systemic resistance and modulates iron deficiency responses in Arabidopsis roots. New Phytol. 204, 368-379. doi: 10.1111/nph.12980

Zamioudis, C., Korteland, J., Van Pelt, J. A., van Hamersveld, M., Dombrowski, N., Bai, Y., et al. (2015). Rhizobacterial volatiles and photosynthesis-related signals coordinate MYB72 expression in Arabidopsis roots during onset of induced systemic resistance and iron-deficiency responses. Plant J. 84, 309-322. doi: 10.1111/tpj.12995

Zeidler, D., Zähringer, U., Gerber, I., Dubery, I., Hartung, T., Bors, W., et al. (2004). Innate immunity in Arabidopsis thaliana: lipopolysaccharides activate nitric oxide synthase (NOS) and induce defense genes. Proc. Natl. Acad. Sci. U.S.A. 101, 15811-15816. doi: 10.1073/pnas.0404536101

Zhang, H., Kim, M. S., Krishnamachari, V., Payton, P., Sun, Y., Grimson, M., et al. (2007). Rhizobacterial volatile emissions regulate auxin homeostasis and cell expansion in Arabidopsis. Planta 226, 839-851. doi: 10.1007/s00425-0070530-2

Zhang, H., Sun, Y., Xie, X., Kim, M. S., Dowd, S. E., and Paré, P. W. (2009). A soil bacterium regulates plant acquisition of iron via deficiency inducible mechanisms. Plant J. 58, 568-577. doi: 10.1111/j.1365-313X.2009. 03803.x

Zhang, J., Liu, B., Li, M., Feng, D., Jin, H., Wang, P., et al. (2015). The bHLH transcription factor bHLH104 interacts with IAA-LEUCINE RESISTANT3 and modulates iron homeostasis in Arabidopsis. Plant Cell 27, 787-805. doi: 10. 1105/tpc.114.132704

Zhang, Y., Wu, H., Wang, N., Fan, H., Chen, C., Cui, Y., et al. (2014). Mediator subunit 16 functions in the regulation of iron uptake gene expression in Arabidopsis. New Phytol. 203, 770-783. doi: 10.1111/nph.12860

Zhao, L., Wang, F., Zhang, Y., and Zhang, J. (2014). Involvement of Trichoderma asperellum strain T6 in regulating iron acquisition in plants. J. Basic Microbiol. 54, S115-S124. doi: 10.1002/jobm.201400148

Zhou, C., Guo, J., Zhu, L., Xiao, X., Xie, Y., Zhu, J., et al. (2016a). Paenibacillus polymyxa BFKC01 enhances plant iron absorption via improved root systems and activated iron acquisition mechanisms. Plant Physiol. Biochem. 105, 162173. doi: 10.1016/j.plaphy.2016.04.025

Zhou, C., Ma, Z., Xiao, X., Xie, Y., Zhu, J., and Wang, J. (2016b). Potential enhancement of plant iron assimilation by microbial-induced root exudation of phenolic compounds. Res. Rev. J. Bot. Sci. 5, 34-37.

Zhou, C., Zhu, L., Ma, Z., and Wang, J. (2017). Bacillus amyloliquefaciens SAY09 increases cadmium resistance in plants by activation of auxin-mediated signaling pathways. Genes 8:E173. doi: 10.3390/genes807 0173

Zhou, C., Zhu, L., Ma, Z., and Wang, J. (2018). Improved iron acquisition of Astragalus sinicus under low iron-availability conditions by soil-borne bacteria Burkholderia cepacia. J. Plant Interact. 13, 9-20. doi: 10.1080/17429145.2017. 1407000

Conflict of Interest Statement: The authors declare that the research was conducted in the absence of any commercial or financial relationships that could be construed as a potential conflict of interest.

Copyright (C) 2019 Romera, García, Lucena, Martínez-Medina, Aparicio, Ramos, Alcántara, Angulo and Pérez-Vicente. This is an open-access article distributed under the terms of the Creative Commons Attribution License (CC BY). The use, distribution or reproduction in other forums is permitted, provided the original author(s) and the copyright owner(s) are credited and that the original publication in this journal is cited, in accordance with accepted academic practice. No use, distribution or reproduction is permitted which does not comply with these terms. 